Article

\title{
Design of Multi-Mode Antenna Array for Use in Next-Generation Mobile Handsets
}

\author{
Naser Ojaroudi Parchin 1,*(D), Haleh Jahanbakhsh Basherlou $2 \mathbb{D}$ and Raed A. Abd-Alhameed ${ }^{1,3}$ (i) \\ 1 Faculty of Engineering and Informatics, University of Bradford, Bradford BD7 1DP, UK; \\ R.A.A.Abd@bradford.ac.uk \\ 2 Bradford College, Bradford BD7 1AY, UK; Hale.Jahanbakhsh@gmail.com \\ 3 Department of Communication and Informatics Engineering, Basra University College of Science and \\ Technology, Basra 61004, Iraq \\ * Correspondence: N.OjaroudiParchin@bradford.ac.uk; Tel.: +44-734-143-6156
}

Received: 31 March 2020; Accepted: 24 April 2020; Published: 25 April 2020

\begin{abstract}
In this study, a new design of a tri-band multiple-input-multiple-output (MIMO) antenna array is proposed for fifth-generation (5G) cellular systems. Its structure is composed of eight identical planar-inverted $\mathrm{F}$ antenna (PIFA) elements placed at different edge corners of the handset mainboard with overall dimensions of $150 \times 75 \mathrm{~mm}^{2}$. The PIFA elements and ground plane of the MIMO antenna system are arranged on the back layer of the platform, which makes the design easy to integrate with the handset circuit. For $\mathrm{S}_{11} \leq-10 \mathrm{~dB}$, the radiation elements of the MIMO design operate at the frequency ranges of $2.5-2.7 \mathrm{GHz}, 3.4-3.75 \mathrm{GHz}$, and $5.6-6 \mathrm{GHz}$ covering the long-term evolution (LTE) $41,42 / 43$, and 47 operation bands, respectively. The array achieves better than $15 \mathrm{~dB}$ return loss results across the three operating bands. The presented antenna array not only exhibits multi-band operation but also generates the polarization diversity characteristic, which makes it suitable for multi-mode operation. The proposed antenna array was simulated and experimentally tested. Fundamental characteristics of the proposed design are investigated. It offers three band S-parameters with acceptable isolation and dual-polarized radiation with quite good efficiency and gain results. Besides this, the total active reflection coefficient (TARC) and envelope correlation coefficient (ECC) results of the PIFAs are very low over the bands. In addition, the radiation characteristics of the MIMO antenna in the presence of the user and handset components are studied. Moreover, a new and compact phased array millimeter-wave (MM-Wave) antenna with broad bandwidth and end-fire radiation is introduced which can be easily integrated into the smartphone antenna system. Due to its good performance and simple structures, the proposed smartphone antenna array design is a good candidate for future multi-mode $5 \mathrm{G}$ cellular applications.
\end{abstract}

Keywords: 5G; future handsets; modified PIFA; multi-antenna system; multi-band operation

\section{Introduction}

With the rapid evolution of wireless communications, the $5 \mathrm{G}$ network has received a great deal of attention from both academia and industry, with many reported efforts and research outputs [1-3]. Significant improvements will be made in different areas, including the data rate speed and resolution, mobility, latency, etc. Multiple-input-multiple-output (MIMO) technology with multiple antennas is a promising technology to obtain the requirements of 5G communications [4-6]. To date, $2 \times 2$ MIMO systems have been successfully employed for $4 \mathrm{G}$ mobile networks, and a larger number of antenna elements is expected to be applied for $5 \mathrm{G}$ communications $[7,8]$. The $5 \mathrm{G}$ system is predicted to possess an aggregate data rate 1000 times faster than $4 \mathrm{G}$, and it has better link reliability. Thus, compared with the $4 \mathrm{G}$ MIMO antenna systems, at least six to eight antenna elements are integrated into 
a mobile terminal for 5G massive MIMO to provide good diversity and multiplexing gain [9]. This can enhance the channel capacity and link system reliability $[10,11]$. The greater number of antennas could make it more resistant to intentional jamming and interference. Through spatial diversity and spatial multiplexing, larger channel capacity and better communication reliability can be achieved. Therefore, the multi-antenna system is much more capable of resisting multipath fading and improving data throughput [12]. The 5G network also needs fundamental technologies to enable small cells, beamforming, full duplexing, MIMO, and millimeter-wave (MM-Wave).

For sub-6 GHz 5G cellular communications, LTE band-41 (2.6 GHz), band-42 (3.5 GHz), band-43 $(3.7 \mathrm{GHz})$, and band $-47(5.8 \mathrm{GHz})$ are the main important candidate frequency bands [13]. Due to the available radio frequency (RF) circuit and test system, $2.6 \mathrm{GHz}$ LTE can be considered as a default for future mobile communications, and it has recently attracted a great deal of interest. Besides this, 3.4-3.8 GHz (LTE band 42/43) is also recognized by many countries as a first step in demonstrating 5G systems. To further support more potential sub-6 GHz frequency bands, LTE band 47, which is also known as the wireless wide area network (WLAN) operation band, can be considered for $5 \mathrm{G}$ massive MIMO antenna design [14,15].

Several smartphone antenna designs with MIMO systems have been proposed recently [16-32]. However, all of these designs either cover only a single-band operation frequency or use a few antenna elements with large sizes which could occupy a huge space of the mainboard. The 5G handset antenna designs introduced in [16-24] only cover a single frequency band. In [25-29], dual-band or wideband arrays are proposed to support two 5G spectrums. Only a few handset antennas with tri-band function are reported in [30-32] for handset applications. However, these antennas have double/quad antenna elements or do not cover important bands such as $2.6 \mathrm{GHz}$. In this study, we introduced a new MIMO antenna with eight-element planar-inverted F antenna (PIFA) elements which, unlike the reported designs, can cover multi-frequency bands simultaneously. In addition, due to the large number of radiators, the proposed handset antenna can be applied for massive MIMO communication [33]. Furthermore, the proposed handset antenna generates the polarization diversity characteristic, which supports both vertical and horizontal polarizations [34-36]. The modified PIFA radiation elements of the design are employed at four corners of the printed circuit board (PCB) to operate at three different frequencies covering the LTE 2600, 42/43, and 47 operation bands. The proposed PIFA array system operates at three different bands-2.6, 3.6, and 5.8 GHz-of sub-6 GHz 5G cellular networks. It exhibits good properties in terms of the fundamental characteristics and could be used in future handsets.

Apart from the sub-6-GHz spectrum, 5G smartphones are also expected to support the MM-Wave spectrum [37]. Compact antennas arranged as an array can be employed in different portions of a smartphone PCB to form linear phased arrays with high gain and directional radiation beams [38-40]. In contrast to conventional antennas, such as patch, slot, or monopole antennas, end-fire antennas are more suitable to achieve the required radiation coverage [41,42]. Phased array antennas with high performance are highly desirable for MM-Wave 5G communications as they can increase the radiation and the connectivity of the system [43-45]. In addition to the proposed MIMO antenna, a new and compact phased array millimeter-wave (MM-Wave) antenna with broad bandwidth and end-fire radiation is introduced for $28 \mathrm{GHz}$ applications. Its configuration is composed of eight loop dipole resonators with pairs of directors arranged in a linear form which can be easily integrated into the smartphone antenna system. The following sections present the design details, single-element performance, characteristics of the tri-band MIMO antenna, and the $28 \mathrm{GHz}$ phased array.

\section{Design and Configuration of the Proposed 5G Antenna Array}

The schematic of the designed MIMO handset antenna is plotted in Figure 1. As shown, it is composed of four PIFA pairs that have been deployed at different corners of the mainboard. The presented handset antenna is designed on an FR-4 dielectric with a relative permittivity of 4.4 , loss tangent of 0.026 and a thickness of $h_{x}=1.6 \mathrm{~mm}$. Each PIFA element is fed by a $50 \mathrm{ohm}$ discrete feeding 
technique extended from the ground plane to the antenna feedline. The values of the design details are listed in Table 1.

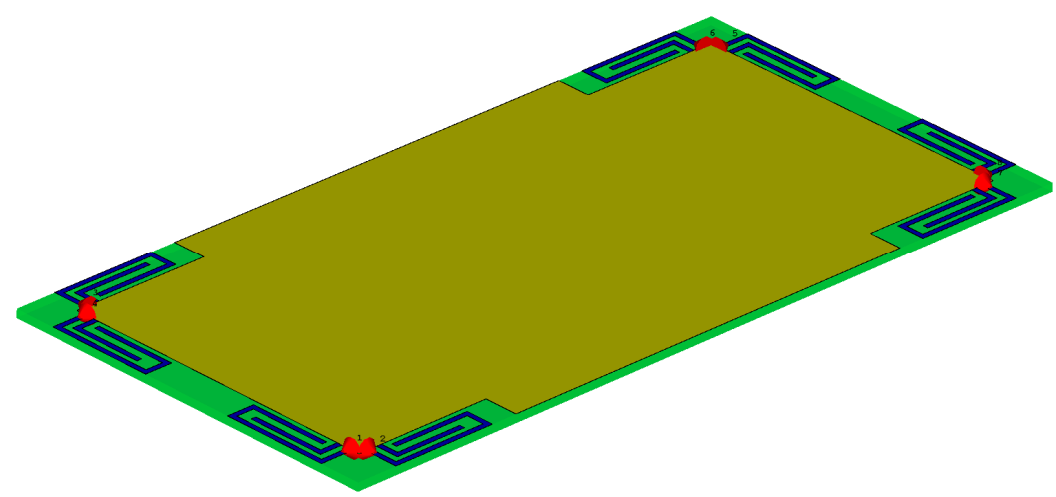

(a)

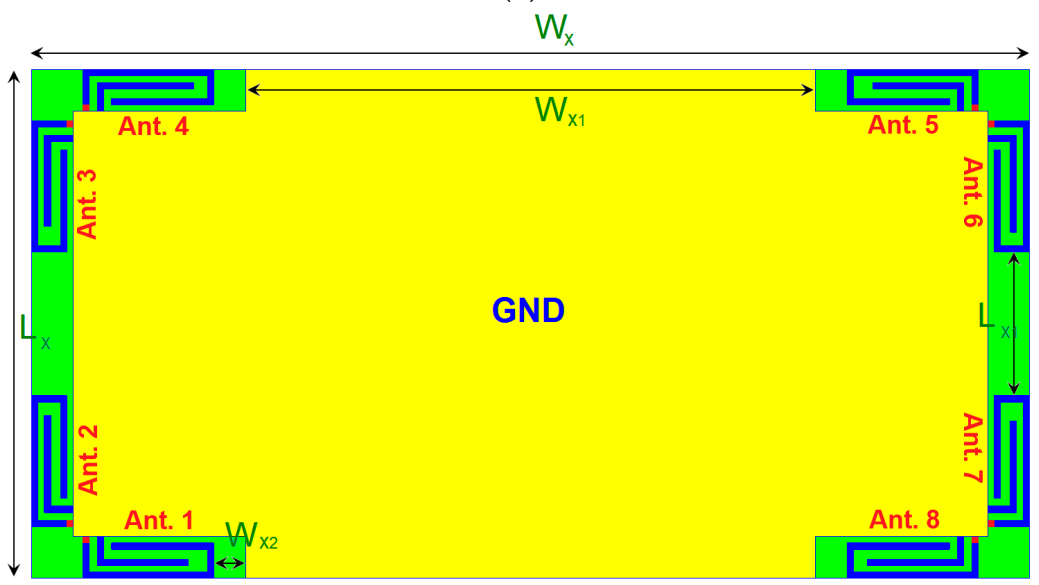

(b)

Figure 1. (a) Side and (b) back views of the multi-mode antenna array.

Table 1. The dimension values of the presented multi-mode array.

\begin{tabular}{ccccccccc}
\hline Parameter & $\mathbf{W}_{\mathbf{X}}$ & $\mathbf{L}_{\mathbf{X}}$ & $\mathbf{W}_{\mathbf{X 1}}$ & $\mathbf{L}_{\mathbf{X} \mathbf{1}}$ & $\mathbf{W}_{\mathbf{X} \mathbf{2}}$ & $\mathbf{W}$ & $\mathbf{L}$ & $\mathbf{W}_{\mathbf{f}}$ \\
\hline Value $(\mathbf{m m})$ & 150 & 75 & 83 & 18 & 5 & 20.5 & 6.5 & 1 \\
Parameter & $\mathrm{L}_{\mathrm{f}}$ & $\mathrm{W}_{1}$ & $\mathrm{~L}_{1}$ & $\mathrm{~W}_{2}$ & $\mathrm{~L}_{2}$ & $\mathrm{~W}_{3}$ & $\mathrm{~L}_{3}$ & $\mathrm{~L}_{4}$ \\
Value $(\mathbf{m m})$ & 1 & 1 & 15.3 & 3.5 & 14.3 & 16 & 5.5 & 4.5 \\
\hline
\end{tabular}

\section{Characteristics of the Single-Element/Multi-Band PIFA Resonator}

The PIFA is a compact size antenna radiator that provides omnidirectional radiation patterns and can be used in hand-held devices [46-48]. The conventional PIFAs exhibit single-band operation. However, the modified designs can cover multi-frequency bands for multi-mode operation [49]. The configuration of the PIFA element is depicted in Figure 2a. Its structure is composed of an open-loop resonator with an L-shaped strip protruding from the ground plane. As shown, it has a low profile with the dimension of $\mathrm{W} \times \mathrm{L}$. A $50 \Omega$ discrete feeding port is employed to excite the antenna. The computer simulation technology (CST) software is used to investigate the properties of the designed mobile-handset antenna [50]. 


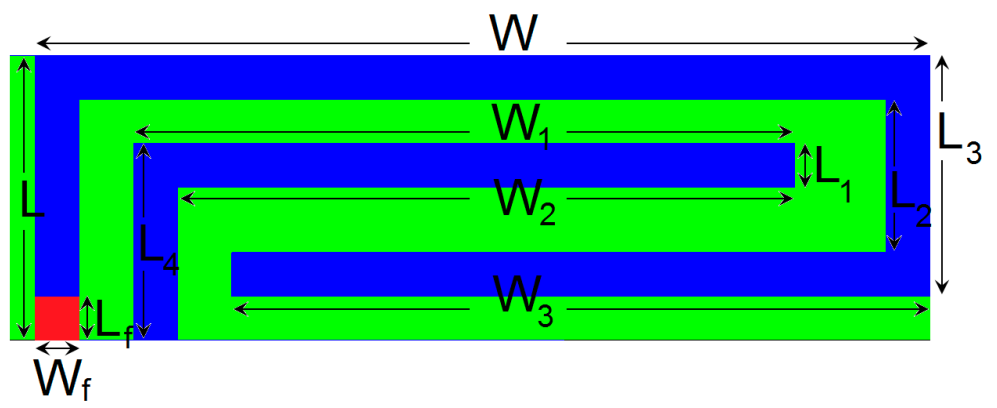

(a)

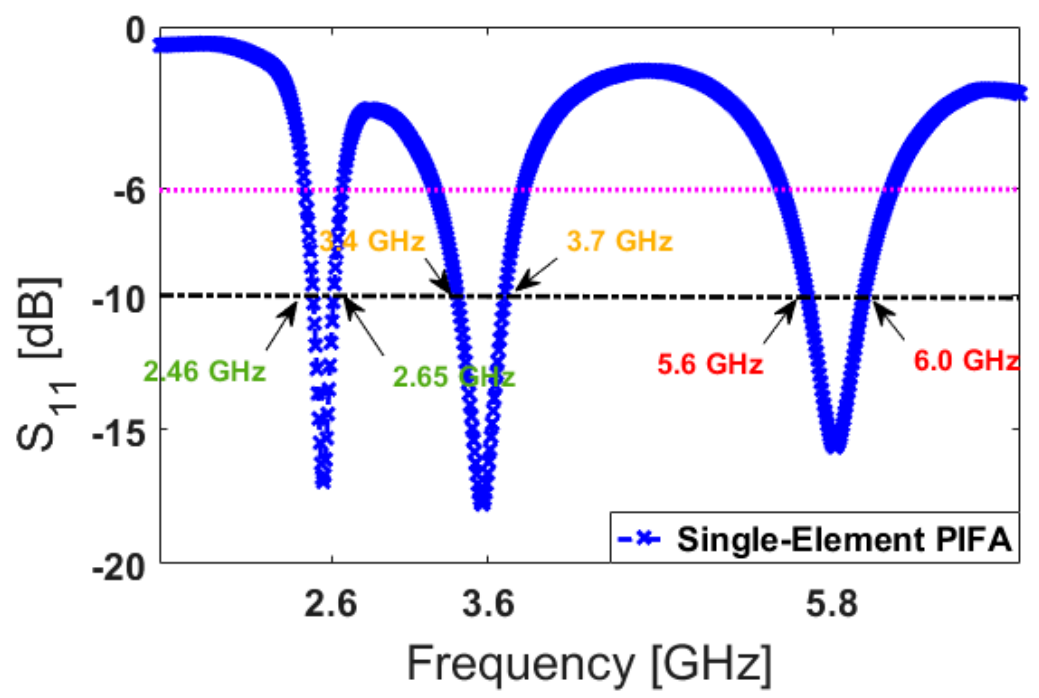

(b)

Figure 2. (a) Transparent view of the planar-inverted $F$ antenna (PIFA) and (b) its $S_{11}$ performance.

The main motive behind the modified PIFA is to obtain a compact antenna element which can support different frequencies and could be integrated with a mainboard circuit while occupying a small clearance. Figure $2 b$ illustrates the simulated reflection coefficient $\left(S_{11}\right)$ characteristic of the PIFA element. As shown, the antenna operates at 2.6, 3.6, and 5.8 GHz and provides wide impedance bandwidths at these frequencies.

In order to justify the tri-band function of the design, the simulated current densities of the modified PIFA element at different operation frequencies are illustrated in Figure 3. It is worth mentioning that the maximum scaling for all figures is the same. At $2.6 \mathrm{GHz}$ (first resonance), as can be seen, the L-shaped strip has high current densities with the maximum distribution. Additionally, the current flow reverses on the interior edge of the surrounded open loop [51]. It is evident that the second resonance of the antenna $S_{11}$ has been achieved using the open-loop resonator as it appears very active at $3.6 \mathrm{GHz}$. The third resonance can be considered as the second harmonic of the first resonance [52]. As shown in Figure 3c, the current distribution is almost equal around the L-shaped strip and the open-loop resonator. Nevertheless, some coupling and interactions between the employed parasitic strip of the modified PIFA can be discovered which could affect the frequency response of the antenna [53].

The main motive behind the PIFA design is to obtain a low-profile and multi-mode radiator with the possibility of integration in the mobile-handset mainboard. The $S_{11}$ characteristics of the modified PIFA antenna can be adjusted by changing the values of the fundamental antenna parameters [54,55]. The first resonance (at $2.6 \mathrm{GHz}$ for the low-band) is mainly determined by the L-shaped strip. The second and third resonances (at 3.6 GHz and 5.8 GHz) depends on the main resonator (open-loop). 
Therefore, the circumference lengths of the resonators can satisfy the dielectric wavelength at the corresponding frequency points [56].

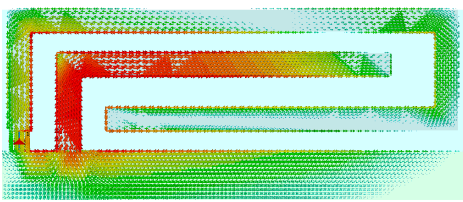

(a)

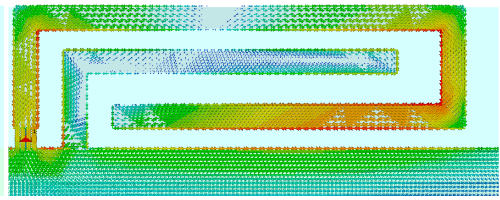

(b)

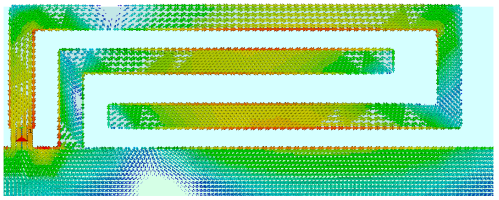

(c)

Figure 3. Surface current densities at (a) $2.6 \mathrm{GHz}$, (b) $3.6 \mathrm{GHz}$, and (c) $5.8 \mathrm{GHz}$.

Figure 4 illustrates the antenna $\mathrm{S}_{11}$ characteristic of varying design parameters including $\mathrm{W}_{3}, \mathrm{~L}_{4}$, $\mathrm{W}_{2}$, and $\mathrm{W}$. In the simulation of the designed antenna, when one parameter changes, the rest of the parameters are kept the same as listed in Table 1 . The antenna $S_{11}$ results for different values of $W_{3}$ are illustrated in Figure 4a. As evident from the figure, there is very little impact on the first resonance, while the second and third resonant frequencies are influenced and tuned to higher frequencies. Figure $4 \mathrm{~b}$ shows that $\mathrm{L}_{4}$ (unlike $\mathrm{W}_{3}$ ) has a significant impact on the first resonance frequency and little effect on the second and third resonance frequencies. Figure $4 \mathrm{c}$ shows the effects of $W_{2}$ (length of L-shaped strip) on the $S_{11}$ of the antenna. It can be observed that as $W_{2}$ decreases from 12.65 to $15.65 \mathrm{~mm}$, the first and third resonances at $2.6 \mathrm{GHz}$ and $5.8 \mathrm{GHz}$ shift up to higher frequencies, while very little variation is observed at the middle resonance frequency $(3.6 \mathrm{GHz})$. The antenna $S_{11}$ characteristic of the antenna at different frequencies is also highly dependent on the length of the open-loop resonator $(\mathrm{W})$. As shown in Figure $4 \mathrm{~d}$, changing the value of $\mathrm{W}$ affects all three resonances of the antenna at different operation bands. According to the obtained results, it can be calculated that the antenna frequency response in all operation bands is very flexible to be tuned to lower or upper frequencies. In addition, its impedance matching can be also affected by changing the parameter values $[57,58]$.

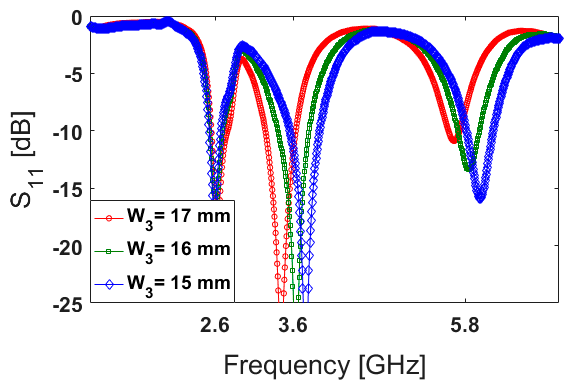

(a)

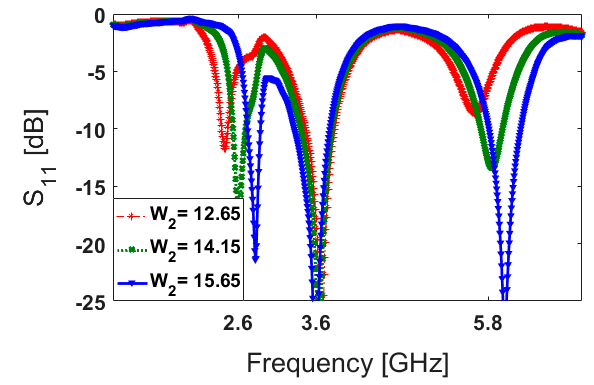

(c)

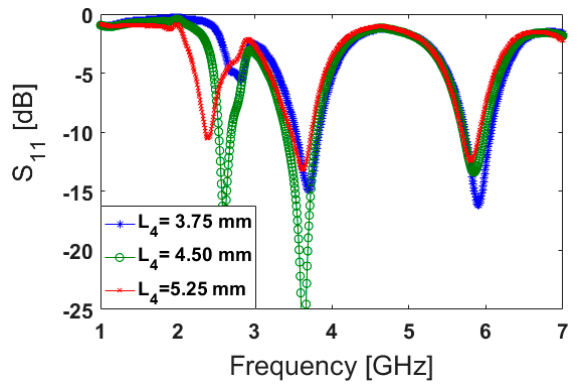

(b)

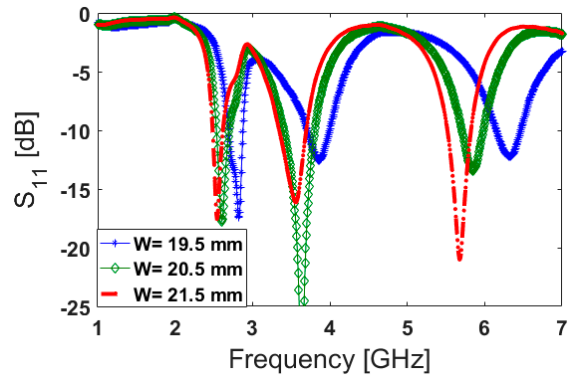

(d)

Figure 4. The $S_{11}$ characteristics for different sizes of (a) $\mathrm{W}_{3}$, (b) $\mathrm{L}_{4}$, (c) $\mathrm{W}_{2}$, and (d) W. 
The fundamental radiation characteristics of the modified PIFA design including the radiation efficiency (R.E.), total efficiency (T.E.) and maximum gain (M.G.) are studied in Figure 5. In theory, the radiation and total efficiencies are related according to

$$
e=e_{r} e_{c d}
$$

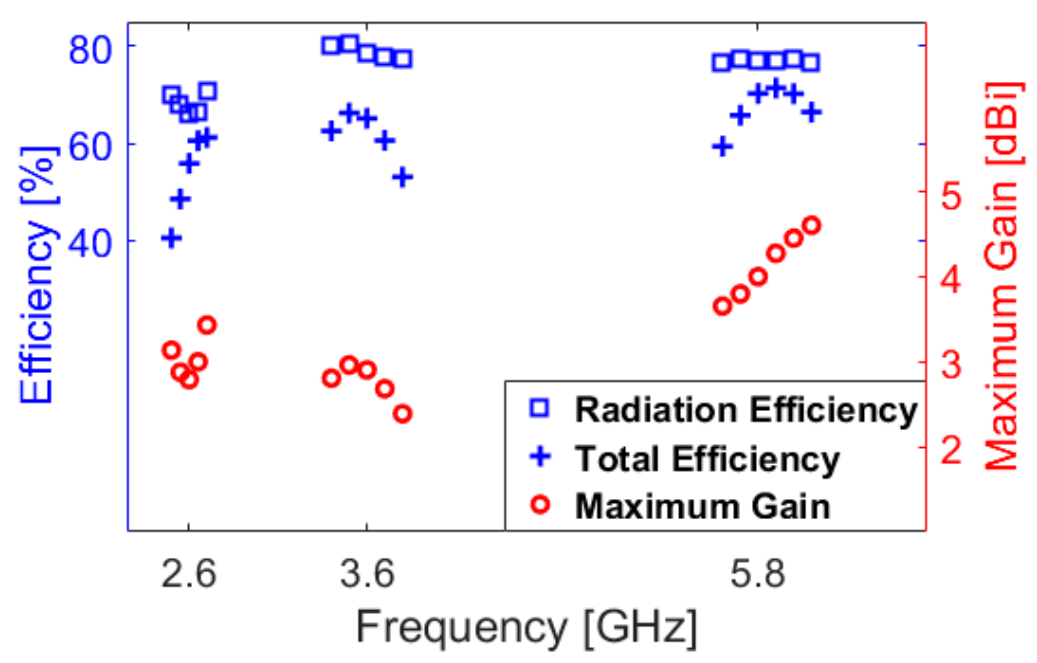

Figure 5. Radiation characteristics of the PIFA element versus its operation bands.

The antenna gain can be calculated using the radiation efficiency and the directivity as follows:

$$
G_{0}(d B)=10 \log \left(e_{c d} D_{0}\right)
$$

where $e_{0}$ is the total efficiency, $e_{r}$ is the reflection (mismatch) efficiency $=(1-|\Gamma| 2), e_{c d}$ is the radiation efficiency and $D_{0}$ is the antenna directivity [59]. As can be observed from Figure 5, the antenna provides better than $40 \%$ and $65 \%$ radiation and total efficiencies over the three operation bands. In addition, the maximum gain of the design varies from 2.5 to $4.5 \mathrm{dBi}$.

\section{Characteristics of the Handset Antenna Array}

Figure 6 shows the S parameters of the designed handset antenna. As illustrated, the antenna exhibits good $S$ parameters at three operation bands with acceptable mutual coupling at less than -10 $\mathrm{dB}[5,60]$. According to the obtained results in Figure 6, slight variation can be observed in the $S_{\mathrm{nn}}$ results of the antenna elements, especially in the lower band $(2.6 \mathrm{GHz})$. This variation is mainly due to different placements, feeding points, neighboring, and also unsymmetrical configurations of the employed elements in the main design (smartphone PCB), as shown in Figure 1. Besides this, the smartphone PCB is in a rectangular shape (with a size of $150 \times 75 \mathrm{~mm}^{2}$ ) which could cause some discrepancies on the frequency responses and couplings, mainly between even and odd port numbers (antennas 1 and 2, for example). However, due to the flexible frequency behavior of the antenna elements (explained in Figure 4), by modifying the design parameters of the antenna element, the frequency response can be easily adjusted to the desired frequency bands [61]. 


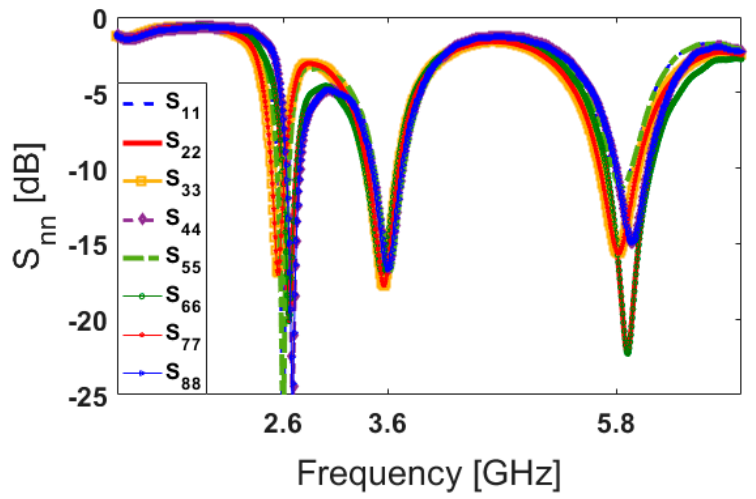

(a)

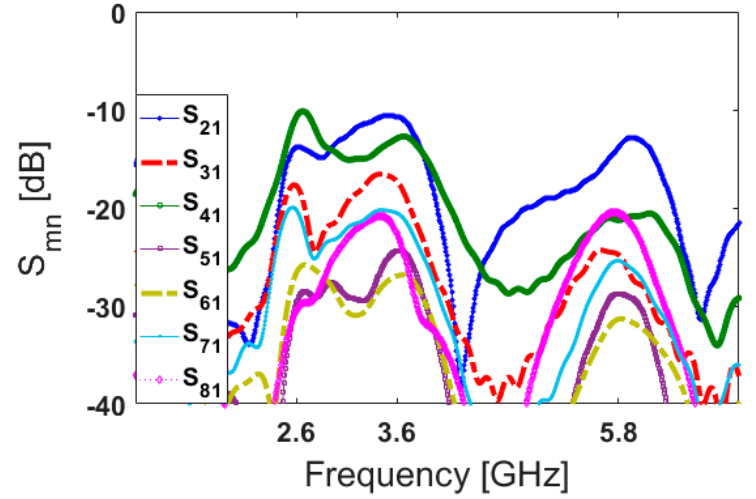

(b)

Figure 6. (a) $S_{n n}$ and (b) $S_{m n}$ properties of the proposed $5 G$ handset antenna.

The side view of the design radiation patterns for a single-element radiator at different operation frequencies is illustrated in Figure 7. Clearly, the antenna radiation elements exhibit high symmetric radiation patterns covering the different sides of the handset mainboard and increasing the radiation coverage [62-65]. The 3D radiation patterns for the eight PIFAs of the main design are displayed in Figure 8. As illustrated, the gain level of the design varies from 3 to more than $4 \mathrm{dBi}$. Besides, due to the placements of the PIFA element, four horizontally and vertically polarized radiation patterns are achieved to improve the MIMO performance of the design [66,67].

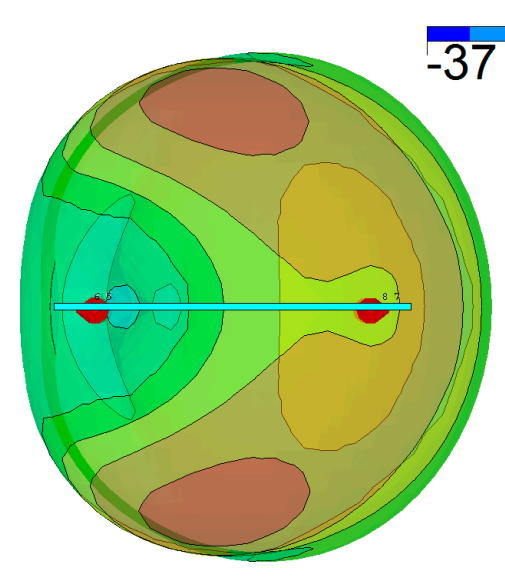

(a)

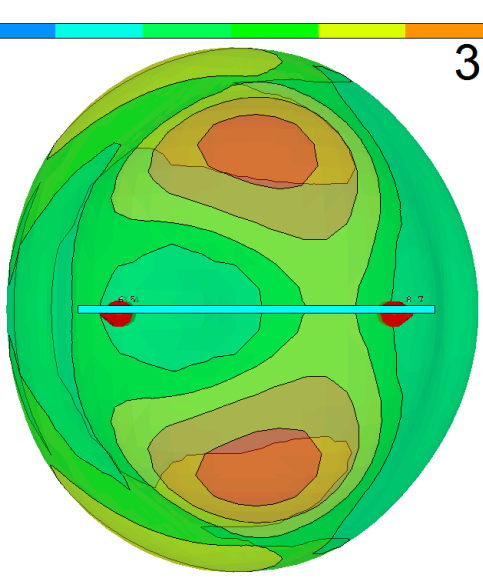

(b)

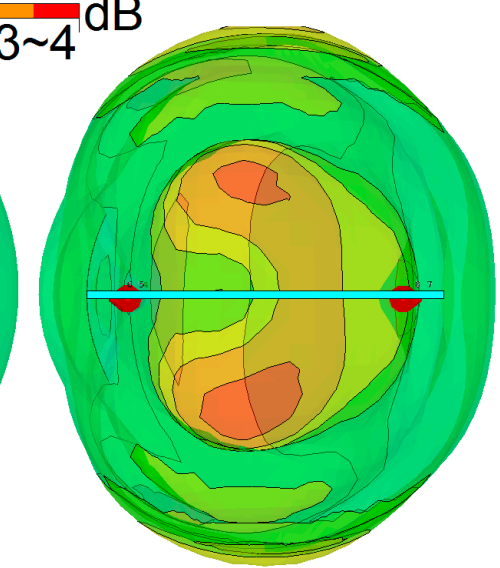

(c)

Figure 7. Side views of the antenna radiation patterns at (a) first $(2.6 \mathrm{GHz}),(\mathbf{b})$ second $(3.6 \mathrm{GHz})$, and (c) third $(5.8 \mathrm{GHz})$ resonances.

The envelope correlation coefficient (ECC) and total active reflection coefficient (TARC) characteristics are substantial in MIMO/diversity antenna systems [68,69]. These parameters can be extracted from the S-parameter results using the below formulas, respectively:

$$
\begin{gathered}
E C C=\frac{\left|S_{m m}^{*} S_{n m}+S_{m n}^{*} S_{n n}\right|^{2}}{\left(1-\left|S_{m m}\right|^{2}-\left|S_{m n}\right|^{2}\right)\left(1-\left|S_{n m}\right|^{2}-\left|S_{n n}\right|^{2}\right)^{*}} \\
\text { TARC }=-\sqrt{\frac{\left(S_{m m}+S_{m n}\right)^{2}+\left(S_{n m}+S_{n n}\right)^{2}}{2}}
\end{gathered}
$$


The ECC and TARC results of the presented multi-mode MIMO antenna design are calculated and plotted in Figure 9. As seen from Figure 9a, the calculated ECC results of PIFA pairs are very low over the entire multi-operation bands (less than 0.01). Additionally, it can be observed from Figure $9 \mathrm{~b}$ that the TARC value of the diverse PIFA pairs is less than $-20 \mathrm{~dB}$ at different frequencies.
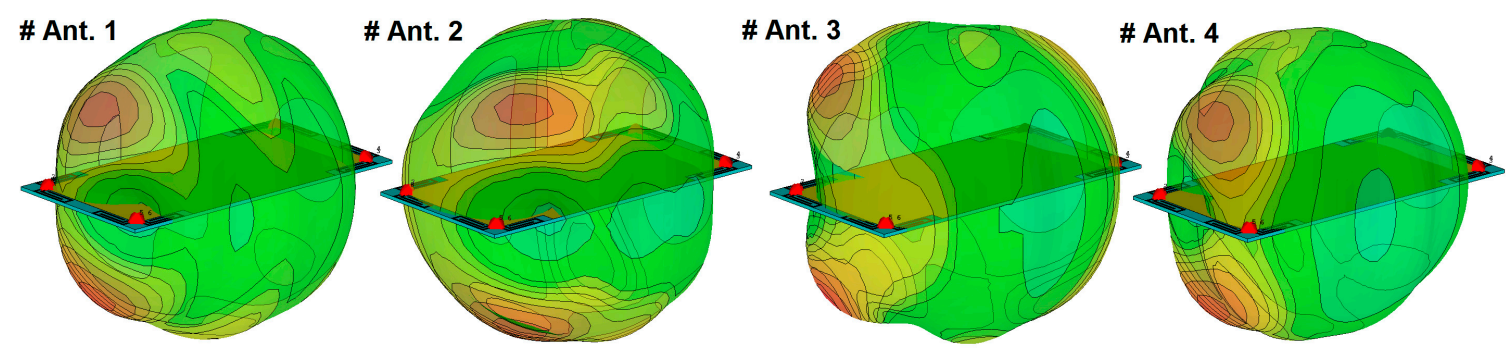

$-36$
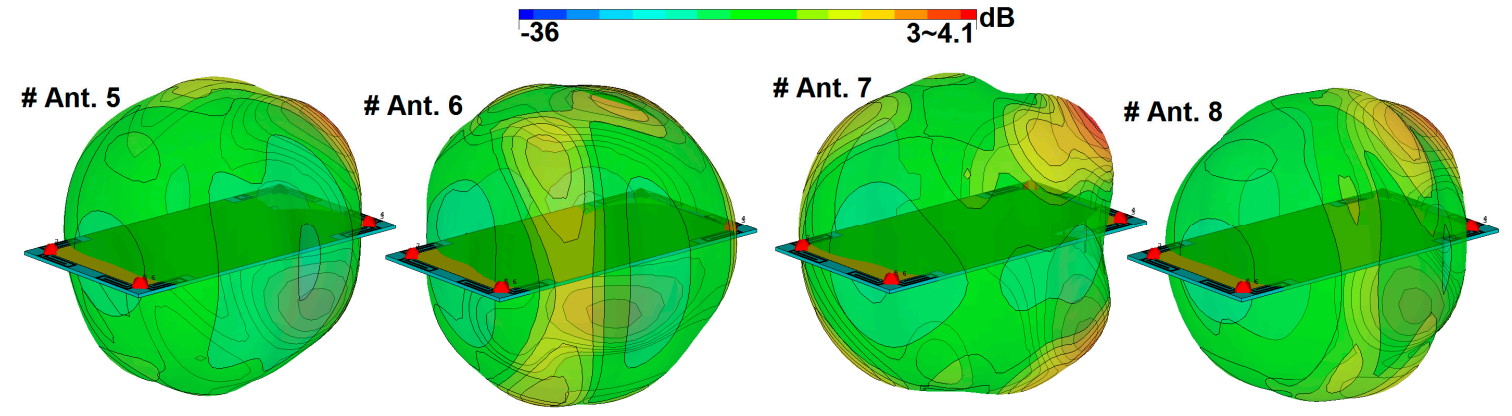

Figure 8. Radiation patterns of the PIFAs at the middle frequency $(3.6 \mathrm{GHz})$.

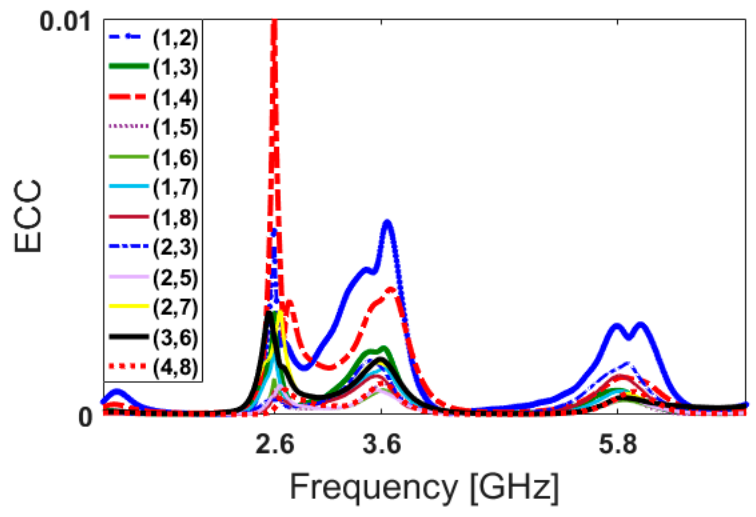

(a)

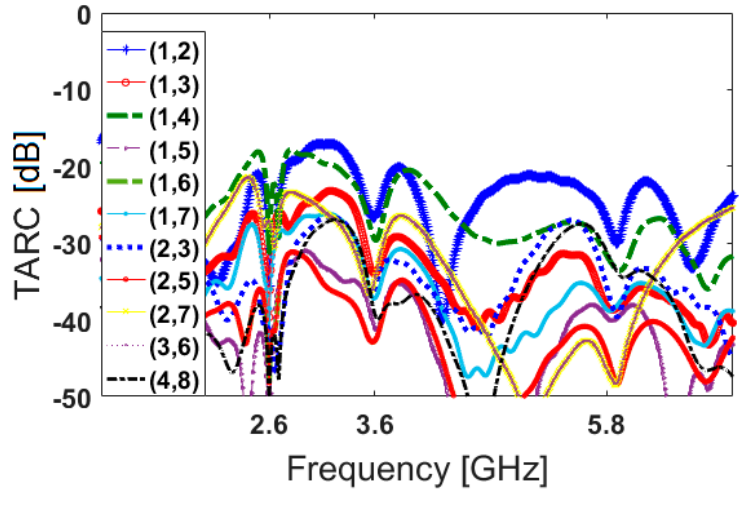

(b)

Figure 9. Calculated (a) ECC and (b) TARC results of the proposed design.

\section{Fabrication and Measurements}

A prototype sample of the proposed 5G handset antenna array was fabricated as illustrated in Figure 10a,b. Due to the similar placements and performances of the modified PIFA pairs, the properties of the handset antenna design for port 1 and 2 are measured and compared below. The feeding mechanism of the adjacent elements is shown in Figure 10c.

The measured and simulated results of the S-parameters are compared in Figure 11a. As seen, the $S_{11} / S_{21}$ measurements have good agreement with the simulated results in terms of covering the required multi-operation bands: a quite good impedance bandwidth $\left(S_{11}<-10\right)$ is achieved to cover the operation bands of 2.45-2.65 GHz, 3.5-3.7 GHz and 5.6-6 GHz with resonances at 2.6, 3.6, and 5.8 GHz, respectively. In addition, as shown, the mutual couplings of the adjacent PIFAs are less than $-15,-10$, 
and $-13 \mathrm{~dB}$ at the desired frequency bands. One of the vital parameters for the MIMO performance of an antenna array is diversity gain (DG), which can be calculated using the following formula:

$$
D G=10 \sqrt{1-(E C C)^{2}}
$$

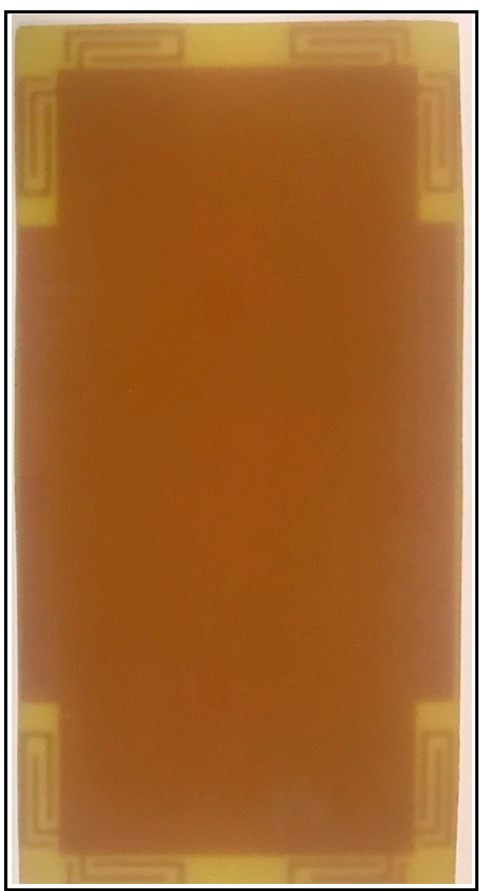

(a)

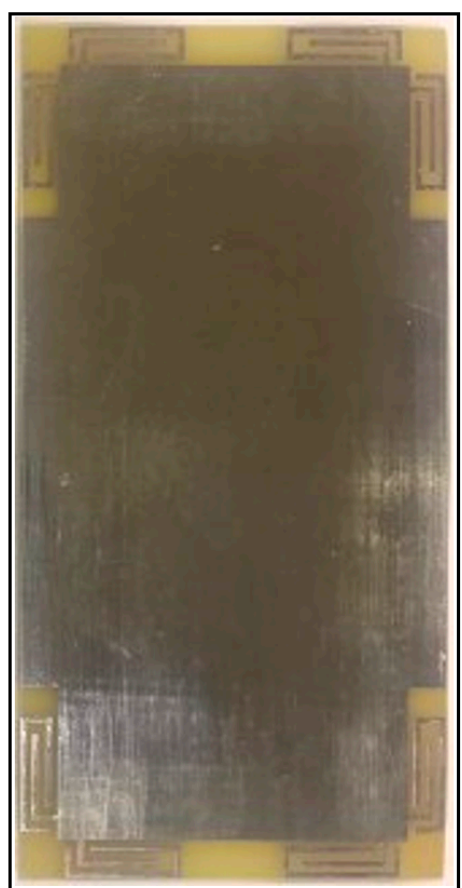

(b)

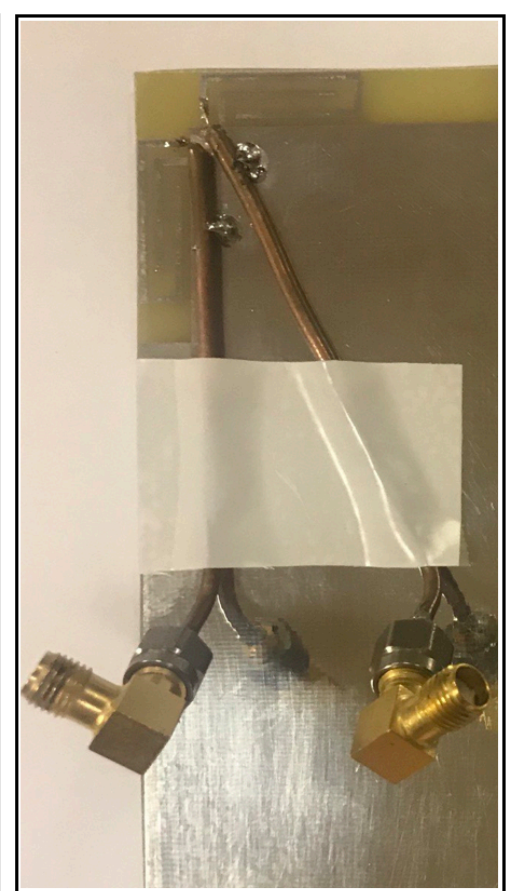

(c)

Figure 10. (a) Front and (b) back views, and (c) feeding mechanism of the fabricated sample.

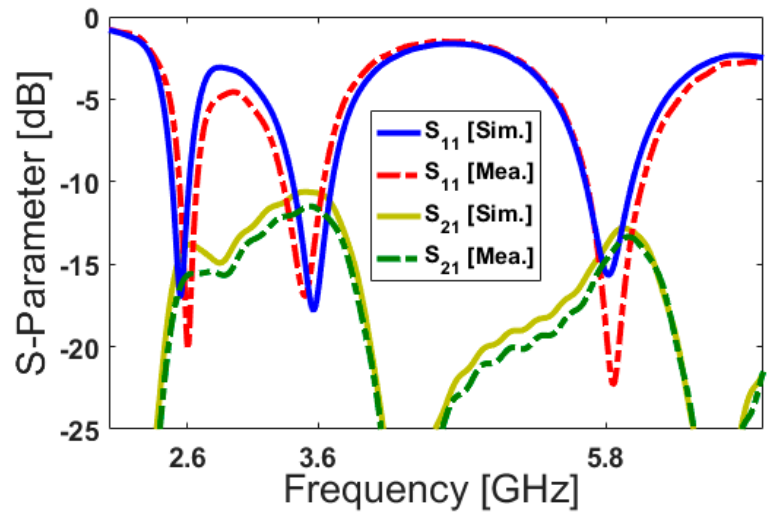

(a)

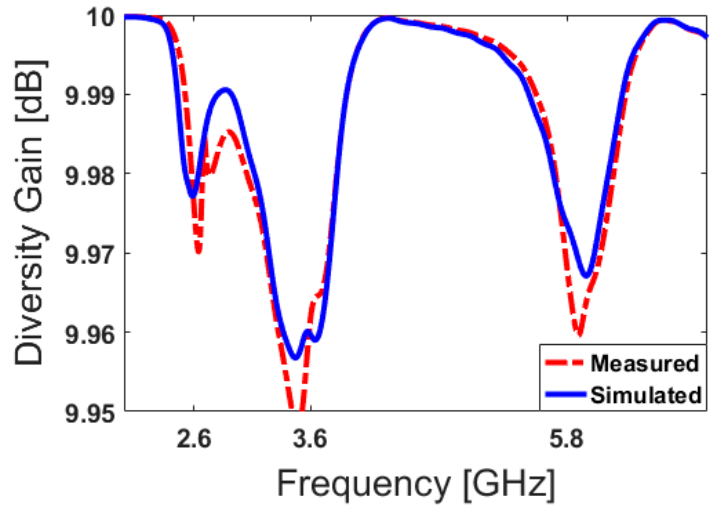

(b)

Figure 11. Measured and simulated (a) S-parameters and (b) diversity gain of the two adjacent PIFAs.

The DG characteristics of the antenna are illustrated in Figure 11b. The diversity gain function of the designed antenna over its operation band is more than $9.95 \mathrm{~dB}$ over the operating frequency bands [70]. In Figure 12a,b, we plot and compare the calculated TARC and ECC results of the PIFA pairs from simulated and measured results. As shown, the ECC function is very low (less than 0.05) over the different frequency bands of interest. Besides, the obtained TARC results are less than $-18 \mathrm{~dB}$. 


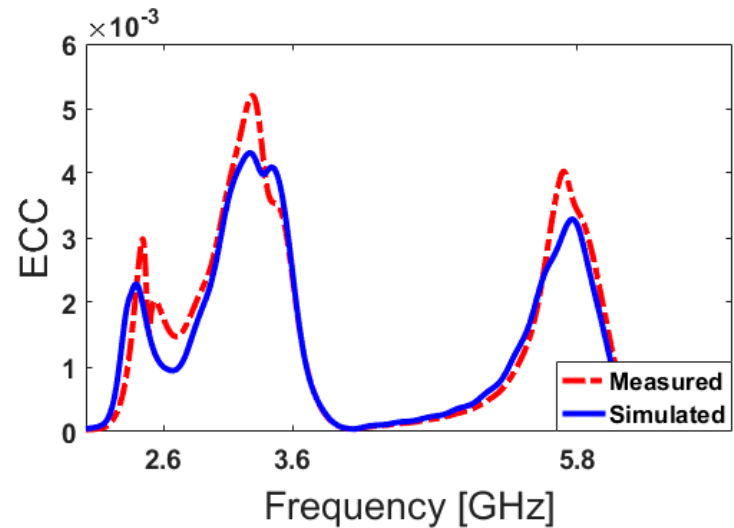

(a)

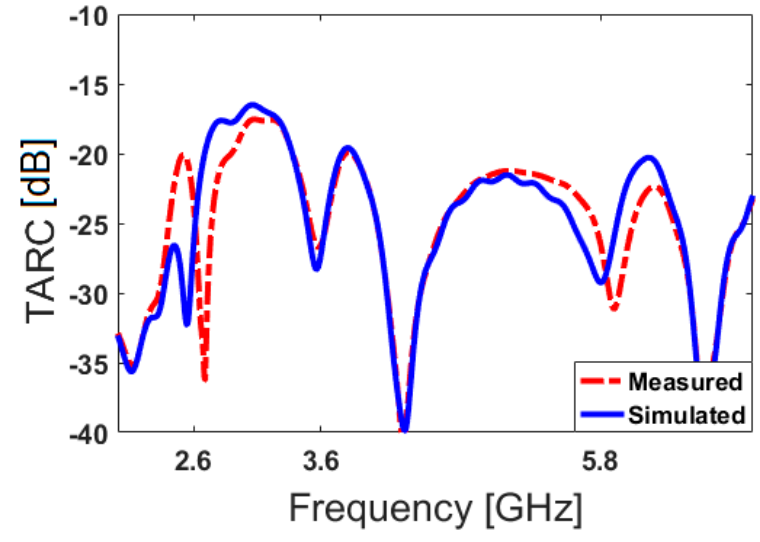

(b)

Figure 12. Calculated (a) ECC and (b) TARC results of the adjacent elements.

Measured and simulated radiation patterns (H-plane) of the modified PIFA element at different frequencies are shown in Figure 13. It is worth noting that, during the measurement of the antenna radiation patterns, one port was kept excited while the other one was loaded with a $50 \Omega$ load. As can be clearly seen, the sample handset antenna prototype provides good quasi-omnidirectional radiation patterns at different resonance frequencies with peak gains and acceptable agreement between simulations and measurements. It is found that when the antenna frequency increases, the gain level of the antenna is increased [71-73].

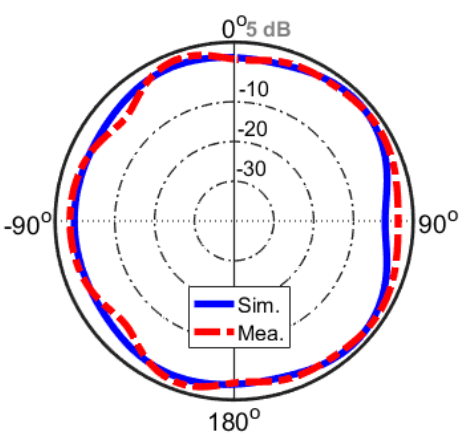

(a)

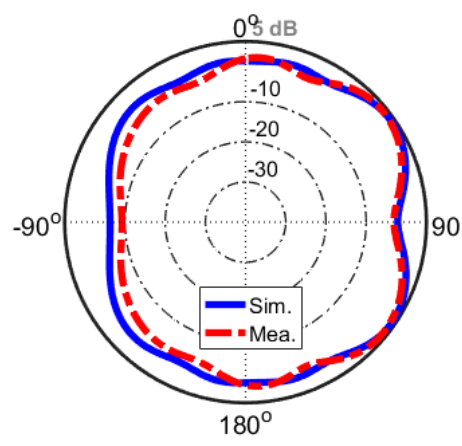

(b)

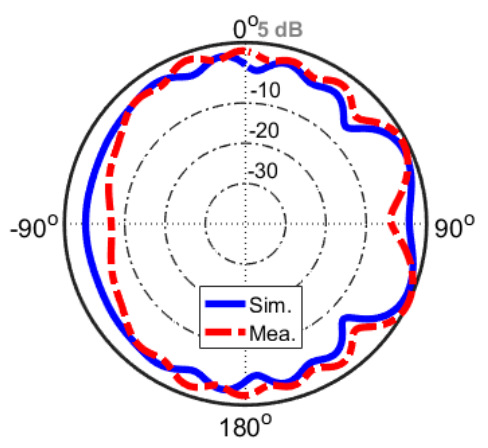

(c)

Figure 13. Two-dimensional radiation patterns at (a) first (2.6 GHz), (b) second (3.6 GHz), and (c) third $(5.8 \mathrm{GHz})$ resonances.

\section{Comparison}

Table 2 compares the characteristics of the proposed handset antenna design and some reported 5G smartphone MIMO antenna designs in the literature with the recent states of the art [16-32]. To the best of our knowledge, most of the reported sub-6 GHz 5G antennas are single-band operating, and only a few works have reported on the use of the dual-band or multi-band techniques for $5 \mathrm{G}$ smartphone applications. The main contribution of our work is that we propose a planar $8 \times 8$ MIMO diversity antenna array with a triple-band function covering the LTE 41, 42/43, and 47 bands. As clearly shown, compared with the recently introduced MIMO handset antenna systems with planar and uniplanar structures, our proposed handset antenna provides better characteristics in terms of impedance matching and bandwidth and low-profile radiators. 
Table 2. Comparison of the design characteristics with the referenced handset antennas. MIMO: multiple-input-multiple-output.

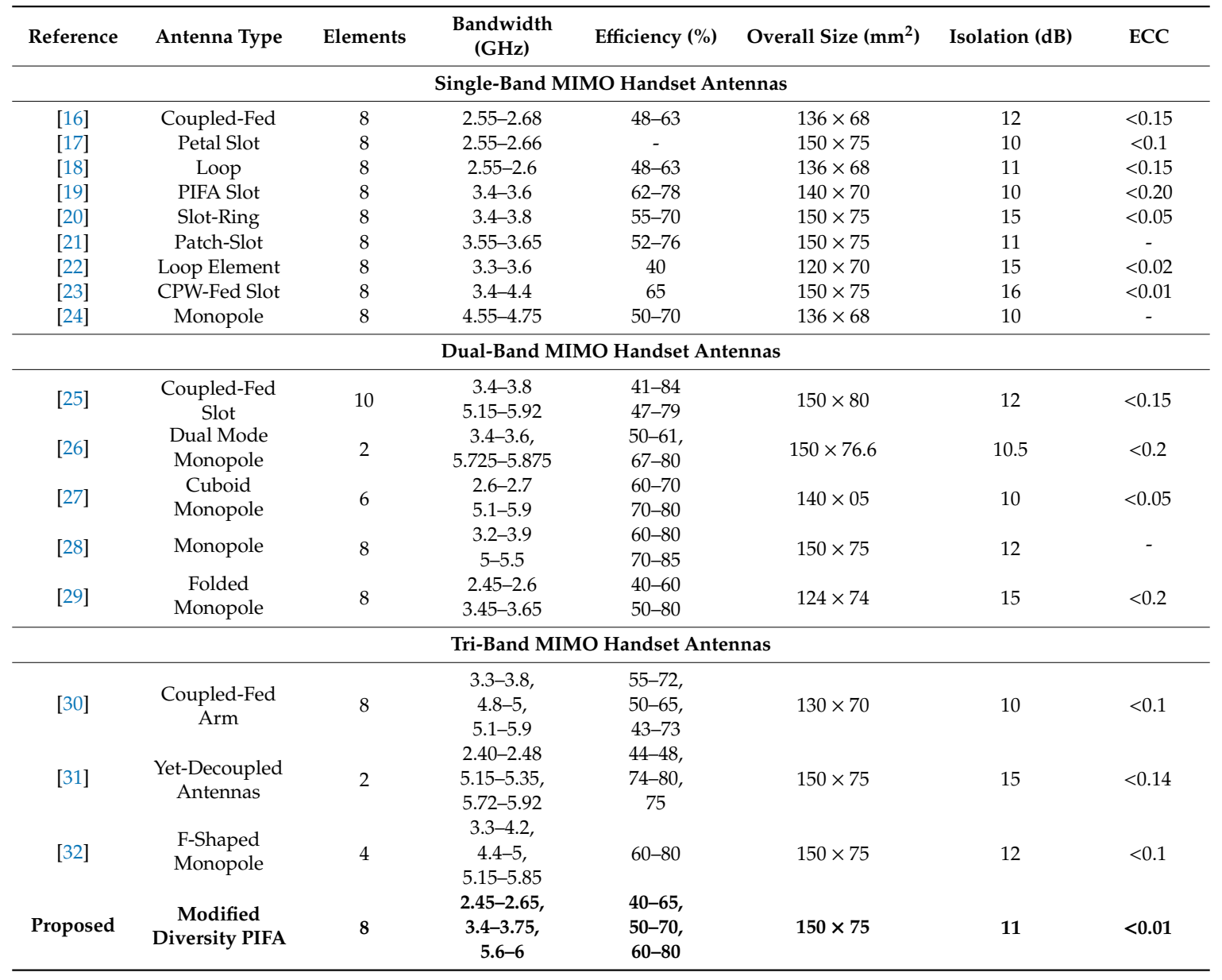

The proposed design achieves improvements not only around tri-band impedance bandwidth but also offers polarization diversity function at different edges of the mainboard. This is mainly due to orthogonal placements of the adjacent PIFA resonators at different corners of the PCB. In addition, unlike the reported handset antennas in the literature, the presented antenna is set on the single (back) layer of the platform which makes the design easy to integrate with the handset circuit. Furthermore, due to the small clearance of the proposed handset antenna, its characteristics in terms of data and talk modes are not changed significantly; that is, the proposed eight-element antenna array has the advantage of the comprehensive performance, meaning that it can be applied well in future 5G mobile terminals.

\section{User Effects on the Characteristics of the Designed Antenna Array}

The health hazards of emitted electromagnetic (EM) radiation from mobile handsets has become a point of open deliberation as the use of mobile handsets is increasing exponentially [74]. For mobile handsets, the investigation of the user-effect on the characteristics of the antenna is indispensable [75]. Below, different usage postures in the data-mode of the user-hand for right and left hands are considered and studied in Figures 14 and 15, respectively. The employed user-hand phantom in the simulation has a relative permittivity of $\varepsilon=24$ and conductivity of $\sigma=2 \mathrm{~s} / \mathrm{m}$ [76]. According to the obtained results, the proposed design exhibits similar radiation behavior for different hand scenarios. This is mainly due to the symmetrical schematic of the designed MIMO antenna. It is shown that the handset antenna and its modified PIFA elements exhibit good efficiencies. Besides, when the antenna frequency increases, the efficiency of the antenna is improved. The reflection coefficients $\left(S_{n n}\right)$ of the proposed 
array are not affected drastically by the hand, except for some small frequency fluctuations. However, the antenna efficiencies of the proposed array are affected significantly owing to the absorption effect of the user's hand. This is because some EM energy has been absorbed by the hand [77]. Compared with the antenna performance in free space, the maximum reductions of the total efficiencies are observed for the PIFA elements that have been partially covered by the hand [78]. Additionally, as evident from the results, the antenna provides good S-parameters including $S_{\mathrm{nn}}$ and $S_{\mathrm{mn}}$ in both right and left-hand scenarios.

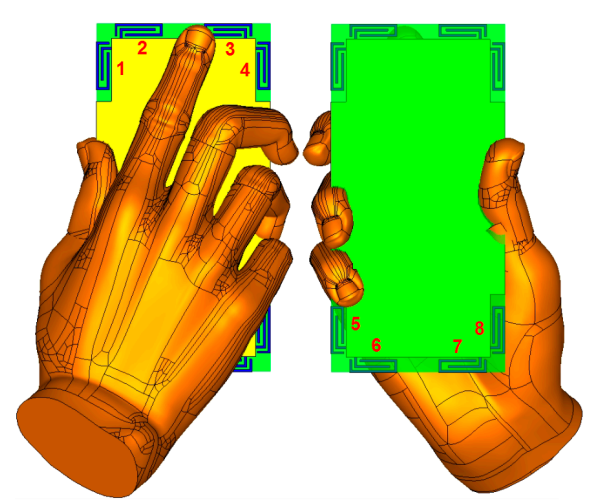

(a)

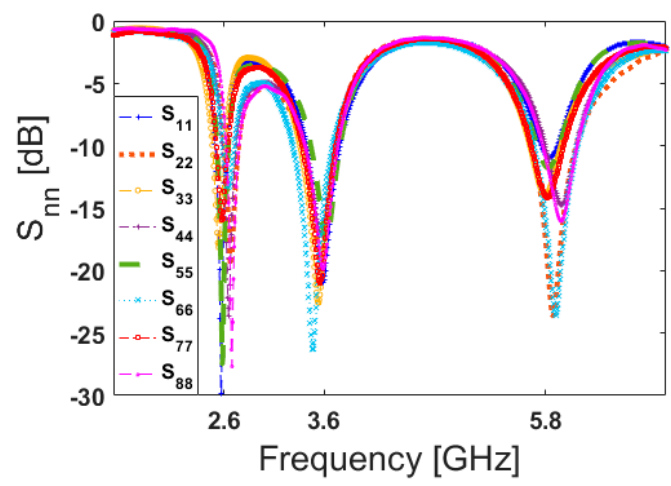

(c)

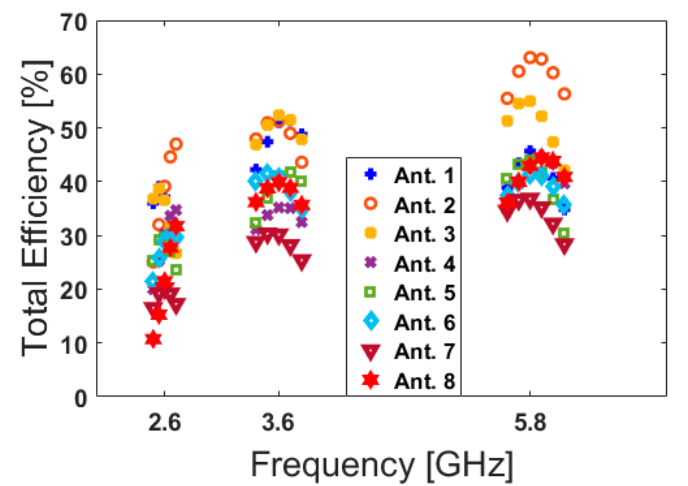

(b)

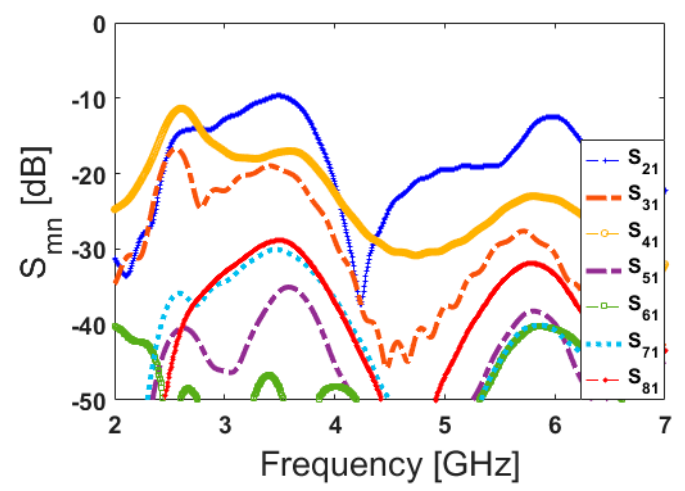

(d)

Figure 14. (a) Placement, (b) total efficiencies, (c) $S_{n n}$, and (d) $S_{m n}$ results for the right-hand scenario.

Apart from the data-mode, the antenna performance in talk-mode should be also studied. Figure 16 shows the total efficiency, $S_{n n}\left(S_{11}-S_{88}\right)$, and $S_{m n}\left(S_{21}-S_{81}\right)$ characteristics of the designed handset antenna in the presence of the user-hand/user-head in talk-mode.

Figure 16a shows the placement of the designed antenna array in talk-mode; the array's total efficiencies are represented in Figure 16b. It is shown that the antenna elements exhibit relatively good efficiencies at different resonance frequencies. Additionally, the antenna S-parameters are depicted in Figure 16d. As can be seen, the PIFAs are operating at the target frequencies with good $S_{n n}$ and less than $-10 \mathrm{~dB} \mathrm{~S}_{\mathrm{mn}}$.

The EM energy absorbed by human body tissues can be evaluated by the specific absorption rate (SAR) $[79,80]$. SAR is a measure of how much power is being absorbed per unit mass. The SAR features of the MIMO design at three different operation frequencies are investigated. According to the obtained results from different investigations of the antenna elements, it is found that antenna 2 causes the maximum SAR value while the minimum SAR value is observed from antenna 6 . The SAR results of antenna 2 and antenna 6 at 2.6, 3.6, and $5.8 \mathrm{GHz}$ are depicted in Figure 17. According to the results, the distance between the PIFA elements and the head phantom is most important in terms of the value of the SAR function. 


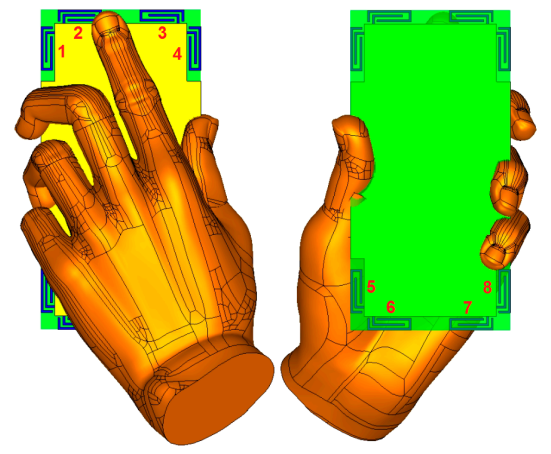

(a)

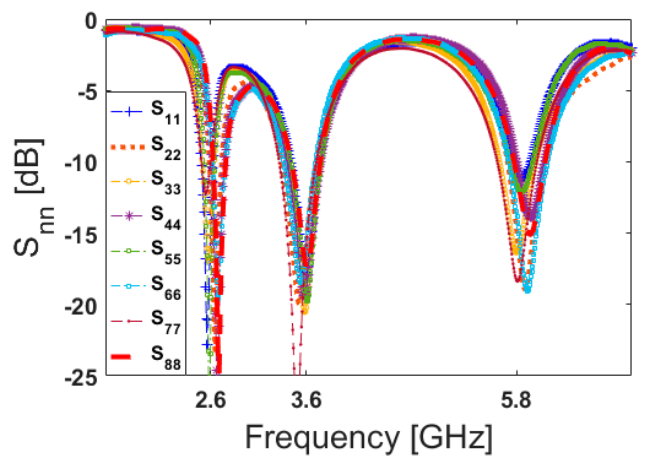

(c)

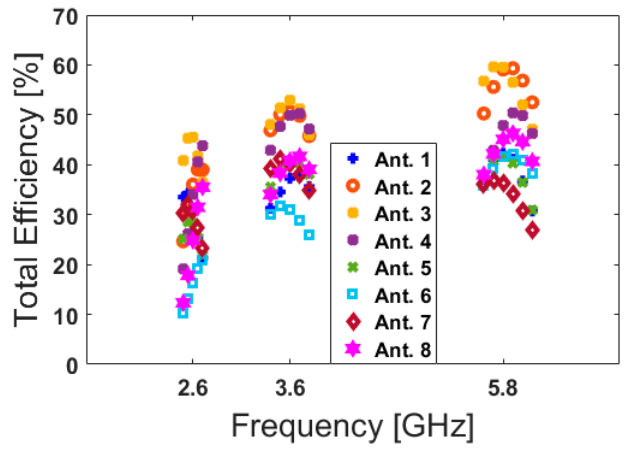

(b)

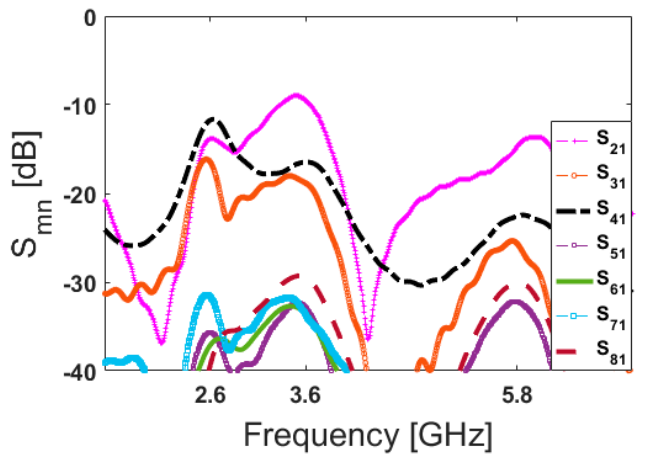

(d)

Figure 15. (a) Placement, (b) total efficiencies, (c) $S_{\mathrm{nn}}$, and (d) $S_{\mathrm{mn}}$ results for the left-hand scenario.

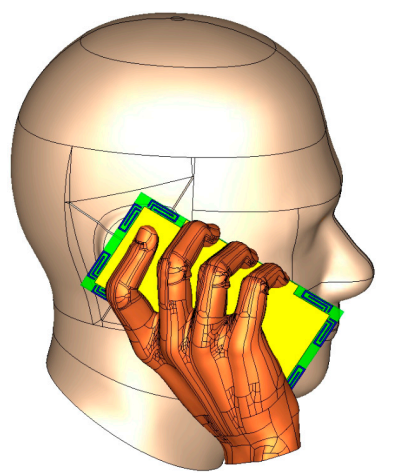

(a)

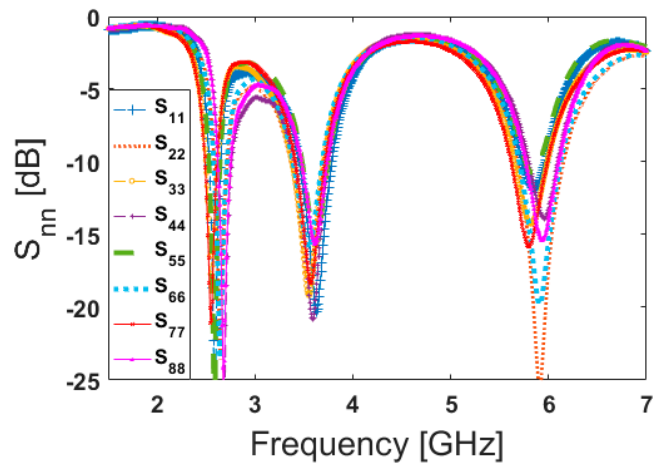

(c)

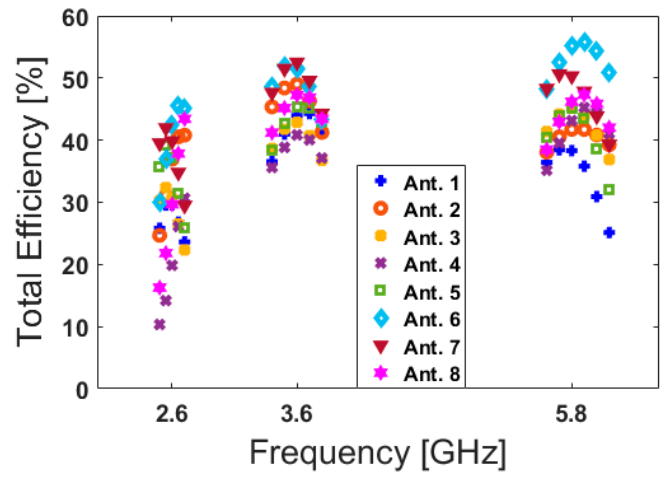

(b)

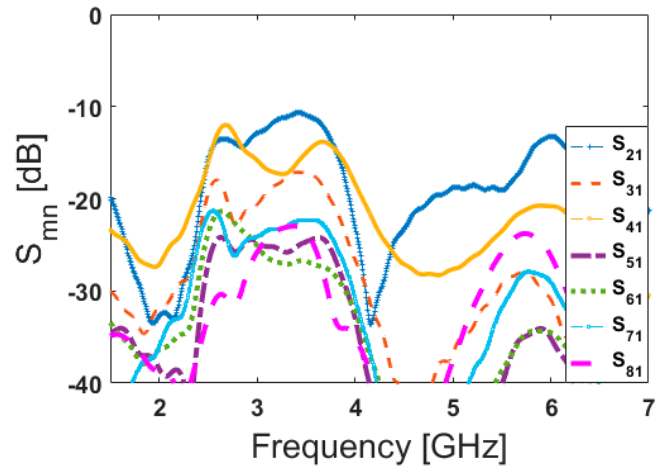

(d)

Figure 16. (a) Placement, (b) total efficiencies, (c) $S_{\text {nn }}$, and (d) $S_{m n}$ results for the talk-mode scenario. 


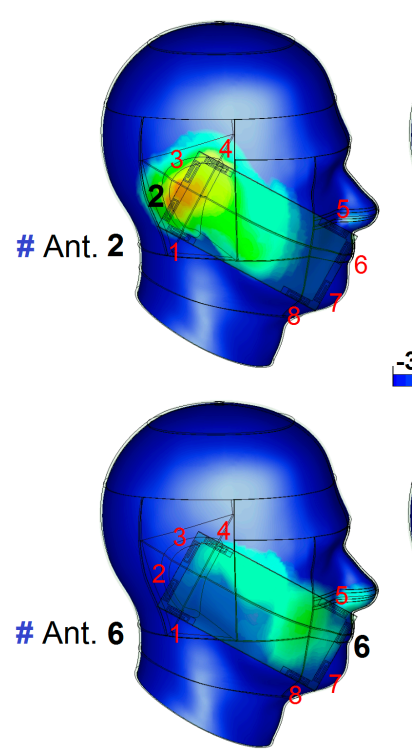

(a)

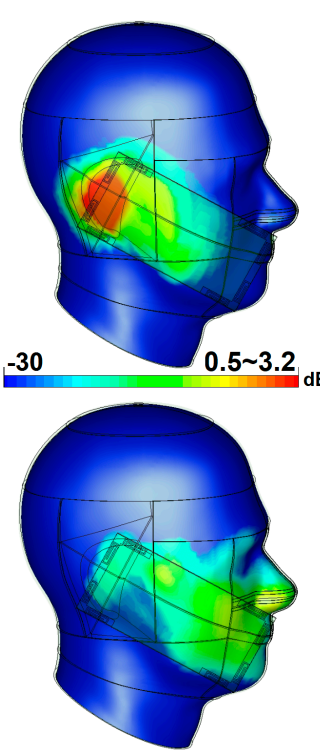

(b)
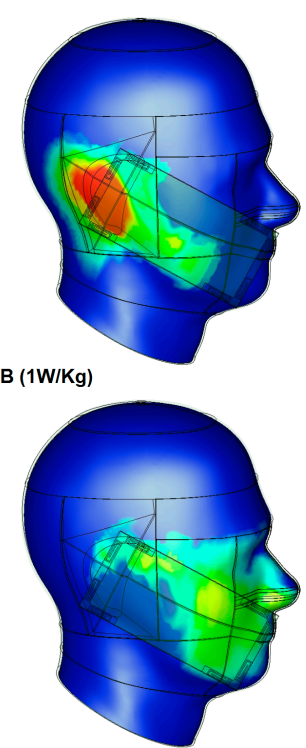

(c)

Figure 17. SAR for antennas 1 and 5 at (a) first $(2.6 \mathrm{GHz}),(\mathbf{b})$ second $(3.6 \mathrm{GHz})$, and (c) third $(5.8 \mathrm{GHz})$ resonances.

Below, the fundamental characteristics of the MIMO antenna including the total efficiency, $\mathrm{S}_{\mathrm{nn}}$ and $\mathrm{S}_{\mathrm{mn}}$ are also studied in the presence of smartphone components including the battery, speaker, camera, USB connector, and LCD screen. Table 3 lists the characteristics of the modeled components [81]. It is clearly seen from Figure 18 that the design provides consistent characteristics at the desired operating frequencies.

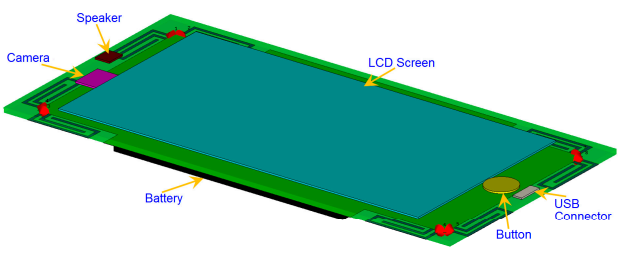

(a)

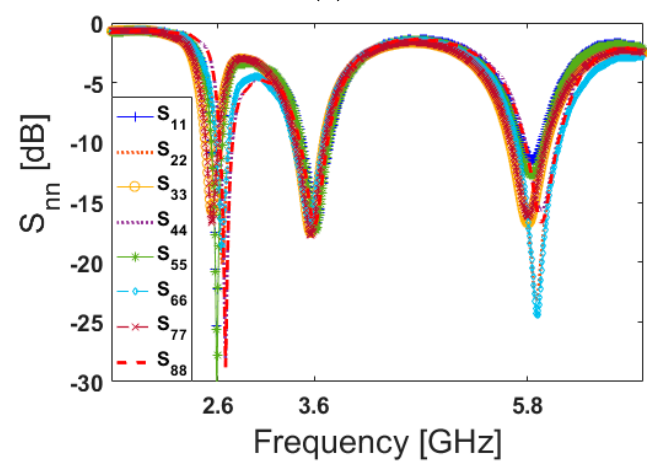

(c)

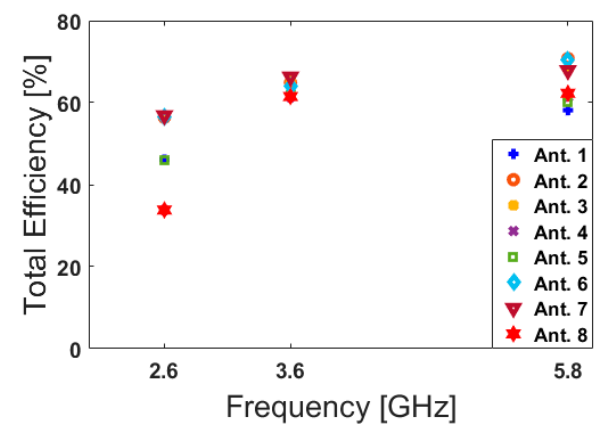

(b)

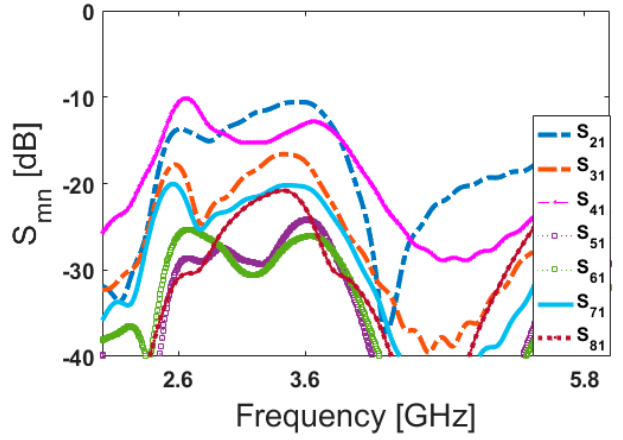

(d)

Figure 18. (a) Placement, (b) total efficiencies, (c) $S_{n n}$, and (d) $S_{m n}$ results in the presence of the smartphone components. 
Table 3. Characteristics of the smartphone components.

\begin{tabular}{ccc}
\hline Component & Material & Permittivity \\
\hline Screen & LCD film & 4.8 \\
Battery. Camera, Speaker & perfect electric conductor (PEC) & - \\
USB Connector & Brass (PEC) & 3.5 \\
Button & Rubber & 4.4 \\
printed circuit board (PCB) & FR-4 & \\
\hline
\end{tabular}

\section{Integration of a Compact MM-Wave Phased Array}

In this section, a new and miniaturized MM-Wave phased array 5G antenna with broad bandwidth is proposed to be incorporated in a shared board. The design details of the integrated phased array are illustrated in Figure 19a. It has a very compact size, with an overall size of $\mathrm{W}_{\mathrm{a}} \times \mathrm{L}_{\mathrm{a}}=18 \times 5 \mathrm{~mm}^{2}$, and it can be implemented in the same FR-4 laminate PCB with a thinner thickness of $0.8 \mathrm{~mm}$. As shown, its configuration is composed of eight loop dipole resonators with pairs of directors arranged in a linear form. A discrete feeding port is applied separately for each antenna. The parameter values (in $\mathrm{mm}$ ) are as follows: $\mathrm{W}_{\mathrm{a} 1}=2.8, \mathrm{~W}_{\mathrm{a} 2}=0.125, \mathrm{~W}_{\mathrm{a} 3}=0.15, \mathrm{~W}_{\mathrm{a} 4}=1.8, \mathrm{~W}_{\mathrm{a} 5}=0.4, \mathrm{~W}_{\mathrm{a} 6}=0.15, \mathrm{~L}_{\mathrm{a} 1}=1, \mathrm{~L}_{\mathrm{a} 2}=1.5$, $\mathrm{L}_{\mathrm{a} 3}=0.2, \mathrm{~d}_{\mathrm{a}}=0.125, \mathrm{~d}_{\mathrm{a} 1}=0.8, \mathrm{~d}_{\mathrm{a} 2}=1.3$. The phased array is designed to work at $28 \mathrm{GHz}$ - one of the promising $5 \mathrm{G}$ candidate bands at higher frequencies $[82,83]$. However, due to the broad bandwidth characteristic, the proposed phased array is also capable of covering 26 and $30 \mathrm{GHz} 5 \mathrm{G}$ bands [84-86].

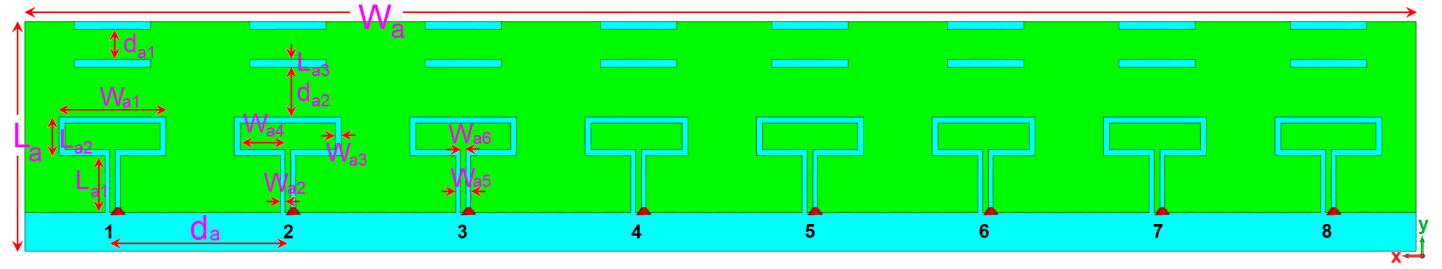

(a)

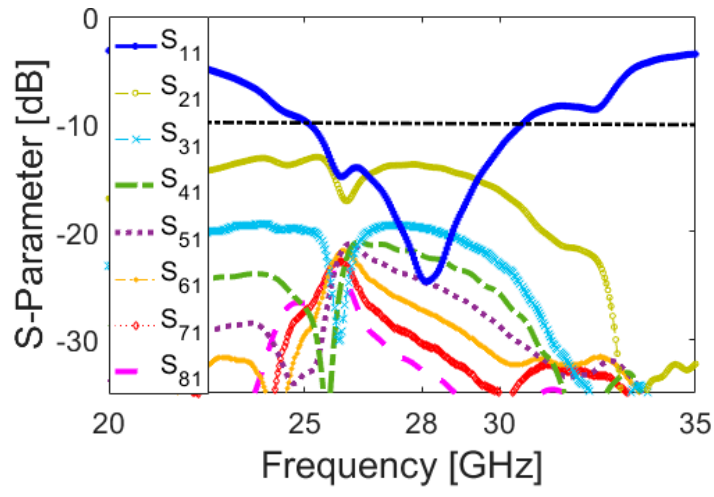

(b)

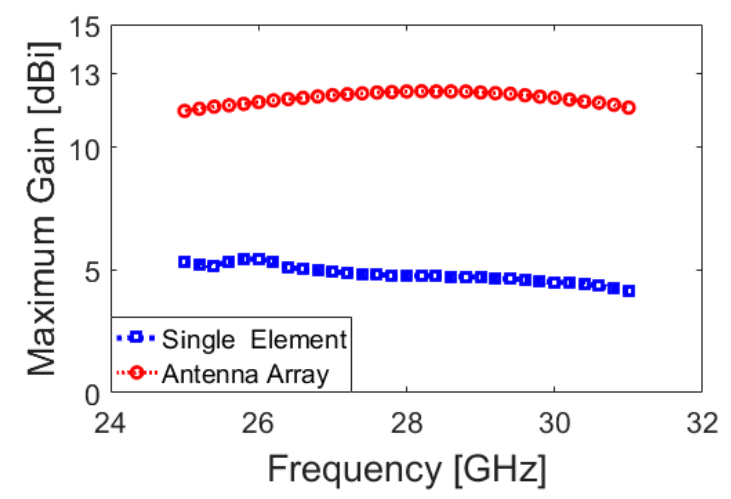

(c)

Figure 19. (a) Design details and configuration of the array, (b) its S-parameters, and (c) gain comparison of the array and the antenna element.

Figure $19 \mathrm{~b}$ plots the S-parameters $\left(\mathrm{S}_{11}-\mathrm{S}_{41}\right)$ of the phased array. As seen, the designed phased array provides a broad impedance bandwidth of $25-31 \mathrm{GHz}$ with a central frequency of $28 \mathrm{GHz}$. Besides, less than a $-15 \mathrm{~dB}$ mutual coupling characteristic is obtained for the antenna elements. Figure $19 \mathrm{c}$ compares the maximum gains of the antenna element and the phased over the operation band. It is shown that the antenna element provides $4 \sim 5 \mathrm{dBi}$ gain values over the operation frequency, whereas more than $12 \mathrm{dBi}$ maximum gain is achieved for the designed array. The 3D beam steering functions of the array at $28 \mathrm{GHz}$ for different angles are plotted in Figure 20a. The shapes and directions of the phased 
array beams are determined by the relative phase amplitudes applied to each antenna element with discrete-feeding ports, as shown below [87]:

$$
\psi=2 \pi\left(\frac{d}{\lambda}\right) \sin \theta
$$

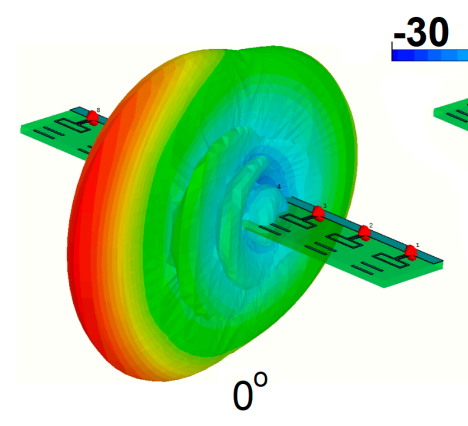

$-30$

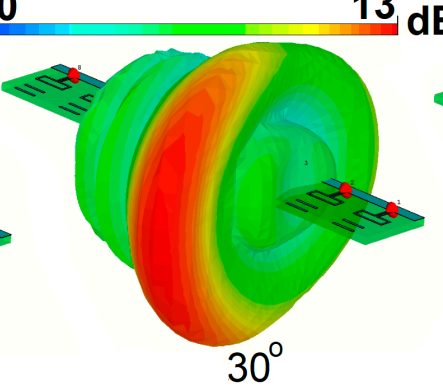

(a)

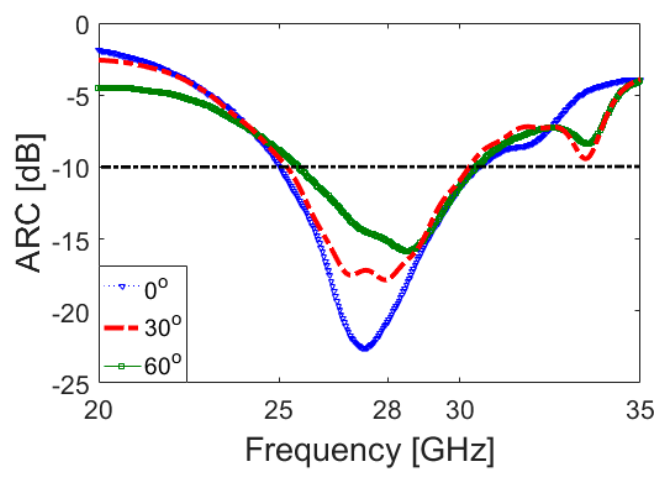

(b)

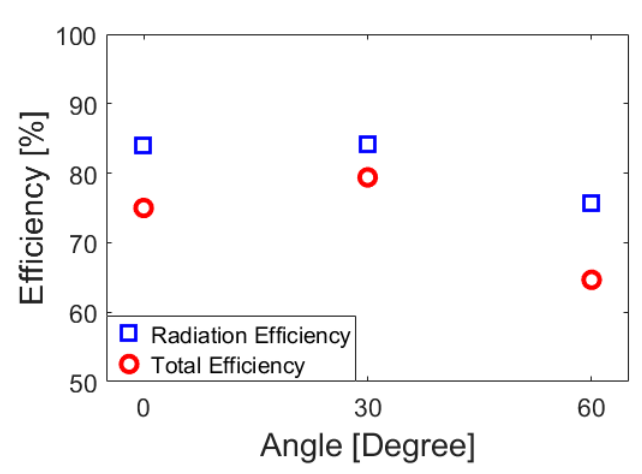

(c)

Figure 20. (a) Radiation beams, (b) active reflection coefficient, and (c) efficiencies at different scanning angles.

As shown, the designed phased array provides a good beam-steering function with end-fire radiation beams. As illustrated, the designed array exhibits high gain radiation beams with low sidelobes.

The active reflection coefficients (ARCs) of the design for different scanning angles are illustrated in Figure 20b. As the radiation beam of the antenna is scanned, the amount of coupling between the radiation elements changes, meaning that the active reflection coefficient curve moves slightly [88]. However, as shown, the proposed phased array antenna exhibits sufficient performance and supports the target frequency bandwidth for different scanning angles. The radiation efficiency of the proposed array antenna is more than $75 \%$ in the operating bandwidth of all switching modes. Figure 20c plots the radiation and total efficiency levels of the array at scanning angles of 0,30 , and 60 . It is shown that the proposed phased array offers quite good efficiency results. Figure 21 shows the possible placements and radiation beam-steering of the proposed phased array in the configuration of the smartphone board. It can be observed that the array can be easily integrated into a small area of the PCB and could provide full radiation coverage supporting different sides of the handset [89]. 


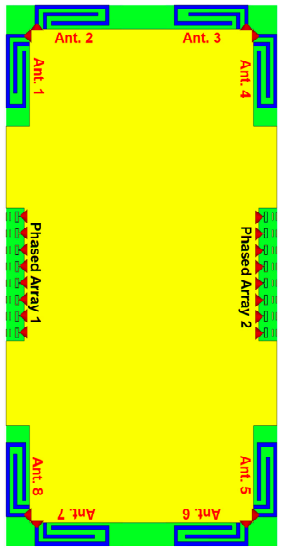

(a)

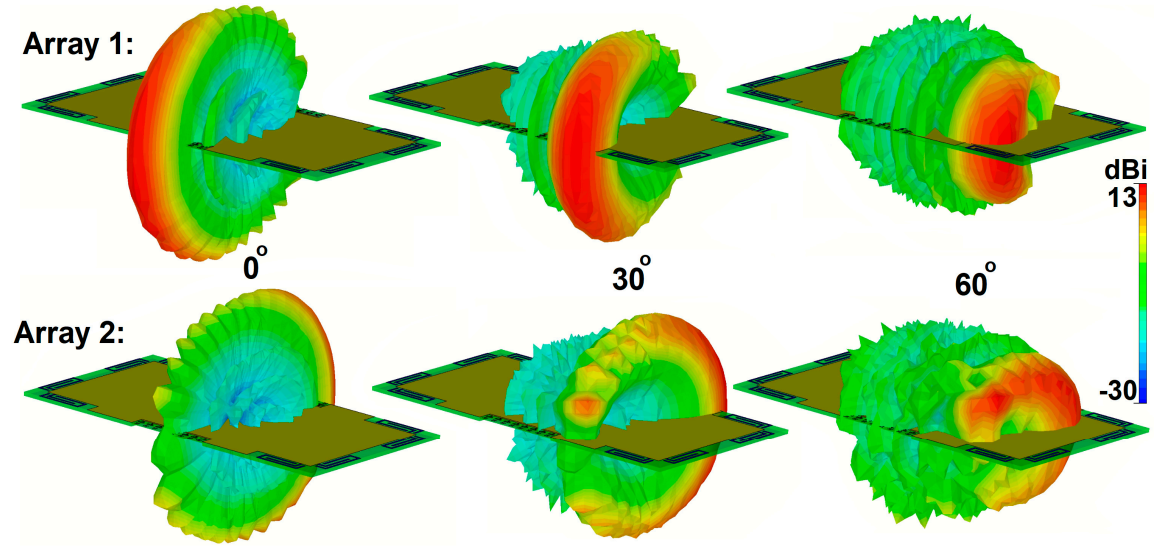

(b)

Figure 21. (a) Different placements of the proposed phased array into the smartphone board and (b) its beam steering function at different angles.

\section{Conclusions}

The design and characteristics of a new MIMO smartphone antenna with a multi-mode operation is successfully investigated in this paper. The designed handset antenna contains eight modified PIFA elements deployed at four corners of the mainboard. The proposed design operates at 2.6, 3.6, and $5.8 \mathrm{GHz}$ for sub- $6 \mathrm{GHz} 5 \mathrm{G}$ mobile terminals. It offers good characteristics in terms of bandwidth, isolation, and radiation patterns. In addition, quite good characteristics are observed in the presence of the user. Due to the tri-band and polarization diversity, the antenna can be considered for multi-mode future handset applications. Furthermore, due to the available space on the smartphone antenna system, a compact $28 \mathrm{GHz}$ phased array is proposed to be integrated onto the 5G smartphone.

Author Contributions: Writing—original draft preparation, N.O.P., H.J.B., and R.A.A.-A.; resources, N.O.P., and R.A.A.-A.; For other cases, all authors have participated. All authors have read and agreed to the published version of the manuscript.

Funding: This project has received funding from the European Union's Horizon 2020 research and innovation program under grant agreement H2020-MSCA-ITN-2016 SECRET-722424.

Acknowledgments: The authors wish to express their thanks to the support provided by the innovation program under grant agreement H2020-MSCA-ITN-2016 SECRET-722424.

Conflicts of Interest: The authors declare no conflict of interest.

\section{References}

1. Nadeem, Q.U.A.; Kammoun, A.; Debbah, M.; Alouini, S.-M. Design of 5G full dimension massive MIMO systems. IEEE Trans. Commun. 2018, 66, 726-740. [CrossRef]

2. Ojaroudiparchin, N.; Shen, M.; Pedersen, G.F. Multi-layer 5G mobile phone antenna for multi-user MIMO communications. In Proceedings of the 23rd Telecommunications Forum Telfor (TELFOR), Belgrade, Serbia, 24-26 November 2015; pp. 559-562.

3. Osseiran, A.; Boccardi, F.; Braun, V.; Kusume, K.; Marsch, P.; Maternia, M.; Queseth, O.; Schellmann, M.; Schotten, H.; Taoka, H.; et al. Scenarios for $5 \mathrm{G}$ mobile and wireless communications: The vision of the METIS project. IEEE Commun. Mag. 2014, 52, 26-35. [CrossRef]

4. Yang, H.H.; Quel, Y.Q.S. Massive MIMO Meet Small Cell. Springer Briefs Electr. Comput. Eng. 2017. [CrossRef]

5. Ojaroudi, N.; Ghadimi, N. Design of CPW-fed slot antenna for MIMO system applications. Microw. Opt. Technol. Lett. 2014, 56, 1278-1281. [CrossRef]

6. Parchin, N.O.; Basherlou, H.J.; Al-Yasir, Y.I.A.; Abd-Alhameed, R.A.; Abdulkhaleq, A.M.; Noras, J.M. Recent developments of reconfigurable antennas for current and future wireless communication systems. Electronics 2019, 8, 128. [CrossRef] 
7. Ojaroudiparchin, N.; Shen, M.; Pedersen, G.F. Wide-scan phased array antenna fed by coax-to- microstriplines for $5 \mathrm{G}$ cell phones. In Proceedings of the 21st International Conference on Microwaves, Radar and Wireless Communications, Krakow, Poland, 9-11 May 2016.

8. Hussain, R.; Alreshaid, A.T.; Podilchak, S.K.; Sharawi, M.S. Compact 4G MIMO antenna integrated with a 5G array for current and future mobile handsets. IET Microw. Antennas Propag. 2017, 11, 271-279. [CrossRef]

9. Andrews, J.G.; Buzzi, S.; Choi, W.; Hanly, S.V.; Lozano, A.; Soong, A.C.K.; Zhang, J.C. What will 5G be? IEEE J. Sel. Areas Commun. 2014, 32, 1065-1082. [CrossRef]

10. Parchin, N.O.; Al-Yasir, Y.I.A.; Abd-Alhameed, R.A. Microwave/RF Components for 5G Front-End Systems; Avid Science: Telangana, India, 2019; pp. 1-200.

11. Chen, Q.; Lin, H.; Wang, J.; Ge, L.; Li, Y.; Pei, T.; Sim, C.-Y.-D. Single ring slot-based antennas for metal-rimmed 4G/5G smartphones. IEEE Trans. Antennas Propag. 2018, 67, 1476-1487. [CrossRef]

12. Bonfante, A.; Giordano, L.G.; López-Pérez, D.; Garcia-Rodriguez, A.; Geraci, G.; Baracca, P.; Majid Butt, M.; Marchetti, N. 5G massive MIMO architectures: Self-backhauled small cells versus direct access. IEEE Trans. Veh. Technol. 2019, 68, 10003-10017. [CrossRef]

13. Gozalvez, J. 5G worldwide developments [mobile radio]. IEEE Veh. Technol. Mag. 2017, 12, 4-11. [CrossRef]

14. 5G in the Sub-6 GHz Spectrum Bands. Available online: http://www.rcrwireless.com/20160815/fundamentals/ 5g-sub-6ghztag31-tag99 (accessed on 15 August 2019).

15. 5G NR (New Radio). Available online: http://3gpp.org/ (accessed on 12 December 2018).

16. Li, M.-Y.; Xu, Z.; Ban, Y.; Yang, Q.; Zhou, Q. Eight-port orthogonally dual-polarized antenna array for 5G smartphone applications. IEEE Trans. Antennas Propag. 2016, 64, 3820-3830. [CrossRef]

17. Parchin, N.O.; Basherlou, H.J.; Al-Yasir, Y.; Abdulkhaleq, A.M.; Abd-Alhameed, R.A.; Excell, P. Eight-port MIMO antenna system for 2.6 GHz LTE cellular communications. Prog. Electromagn. Res. C 2020, 99, 49-59. [CrossRef]

18. Li, M.-Y. Eight-port orthogonally dual-polarised MIMO antennas using loop structures for 5G smartphone. IET Microw. Antennas Propag. 2017, 11, 1810-1816. [CrossRef]

19. Al-Hadi, A.A.; Ilvonen, J.; Valkonen, R.; Viikan, V. Eight-element antenna array for diversity and MIMO mobile terminal in LTE $3500 \mathrm{MHz}$ band. Microw. Opt. Technol. Lett. 2014, 56, 1323-1327. [CrossRef]

20. Parchin, N.O.; Al-Yasir YI, A.; Ali, A.H.; Elfergani, I.; Noras, J.M.; Rodriguez, J.; Abd-Alhameed, R.A. Eight-element dual-polarized MIMO slot antenna system for $5 \mathrm{G}$ smartphone applications. IEEE Access 2019, 9, 15612-15622. [CrossRef]

21. Parchin, N.O.; Al-Yasir, Y.I.A.; Noras, J.M.; Abd-Alhameed, R.A. Dual-polarized MIMO antenna array design using miniaturized self-complementary structures for 5G smartphone applications. In Proceedings of the 13th European Conference on Antennas and Propagation (EuCAP), Krakow, Poland, 31 March-5 April 2019.

22. Jiang, W.; Liu, B.; Cui, Y.; Hu, W. High-isolation Eight-Element MIMO array for 5G smartphone applications. IEEE Access 2019, 7, 34104-34112. [CrossRef]

23. Parchin, N.O.; Basherlou, H.J.; Al-Yasir, Y.; Abdulkhaleq, A.M.; Patwary, M.; Abd-Alhameed, R.A. A new CPW-Fed diversity antenna for MIMO 5G smartphones. Electronics 2020, 9, 261. [CrossRef]

24. Xu, S.; Zhang, M.; Wen, H.; Wang, J. Deep-subwavelength decoupling for MIMO antennas in mobile handsets with singular medium. Sci. Rep. 2017, 7, 12162. [CrossRef]

25. Li, Y.; Sim, C.Y.D.; Luo, Y.; Yang, G. Multiband 10-antenna array for sub-6 GHz MIMO applications in 5-G smartphones. IEEE Access 2018, 6, 28041-28053. [CrossRef]

26. Wong, K.L.; Lin, B.-W.; Li, W.-Y. Dual-band dual inverted-F/loop antennas as a compact decoupled building block for forming eight 3.5/5.8-GHz MIMO antennas in the future smartphone. Microw. Opt. Technol. Lett. 2017, 59, 2715-2721. [CrossRef]

27. Zou, H.; Li, Y.; Shen, H.; Wang, H.; Yang, G. Design of $6 \times 6$ dual-band MIMO antenna array for 4.5G/5G smartphone applications. In Proceedings of the 6th Asia-Pacific Conference on Antennas and Propagation (APCAP), Xi'an, China, 16-19 October 2017; pp. 1-3.

28. Ullah, A.; Parchin, N.O.; Ullah, R.; Abdullah, A.A.S.A.; Danjuma, I.M.; Kosha, J.; Abd-Alhameed, R.A.; Elkhazmi, E.; Elfoghi, E.M.I. Dual-band MIMO antenna system for next generation smartphone applications. In Proceedings of the 2020 IMDC-SDSP, Ankara, Turkey, 8-10 April 2020.

29. Jiang, W.; Cui, Y.; Liu, B.; Hu, W. A Dual-band MIMO antenna with enhanced isolation for $5 \mathrm{G}$ smartphone applications. IEEE Access 2019, 7, 112554-112563. [CrossRef] 
30. Wang, H.; Zhang, R.; Luo, Y.; Yang, G. Compact Eight-Element Antenna Array for Triple-Band MIMO Operation in 5G Mobile Terminals. IEEE Access 2020, 8, 19433-19449. [CrossRef]

31. Wong, K.L.; Tsai, C.Y.; Li, W.Y. Integrated yet decoupled dual antennas with inherent decoupling structures for 2.4/5.2/5.8-GHz WLAN MIMO operation in the smartphone. Microw. Opt. Technol. Lett. 2017, 59, 2235-2241. [CrossRef]

32. Ren, Z.; Wu, S.; Zhao, A. Triple Band MIMO Antenna System for $5 G$ Mobile Terminals. In Proceedings of the 2019 International Workshop on Antenna Technology (iWAT), Miami, FL, USA, 3-6 March 2019; pp. 163-165.

33. Parchin, N.O.; Basherlou, H.J.; Alibakhshikenari, M.; Parchin, Y.O.; Al-Yasir, Y.I.A.; Abd-Alhameed, R.A.; Limiti, E. Mobile-phone antenna array with diamond-ring slot elements for 5G massive MIMO systems. Electronics 2019, 8, 521. [CrossRef]

34. Parchin, N.O.; Ullah, A.; Asharaa, A.S.; Al-Yasir, Y.I.A.; Basherlou, H.J.; Nagala, M.; Abd-Alhameed, R.A.; Noras, J.M. $8 \times 8 \mathrm{MIMO}$ antenna system with coupled-fed elements for $5 \mathrm{G}$ handsets. In Proceedings of the The IET Conference on Antennas and Propagation (APC), Birmingham, UK, 11-12 November 2019.

35. Parchin, N.O.; Basherlou, H.J.; Al-Yasir, Y.I.A.; Ullah, A.; Abd-Alhameed, R.A.; Noras, J.M. Frequency reconfigurable antenna array with compact end-fire radiators for $4 \mathrm{G} / 5 \mathrm{G}$ mobile handsets. In Proceedings of the IEEE 2nd 5G World Forum (5GWF), Dresden, Germany, 30 September-2 October 2019.

36. Parchin, N.O. Multi-band MIMO antenna design with user-impact investigation for 4G and 5G mobile terminals. Sensors 2019, 19, 456. [CrossRef]

37. Rappaport, T.S.; Sun, S.; Mayzus, R.; Zhao, H.; Azar, Y.; Wang, K.; Wong, G.N.; Schulz, J.K.; Samimi, M.; Gutierrez, F. Millimeter-wave mobile communications for 5G cellular: It will work! IEEE Access 2013, 1, 335-349. [CrossRef]

38. Ojaroudiparchin, N.; Shen, M.; Pedersen, G.F. $8 \times 8$ planar phased array antenna with high efficiency and insensitivity properties for 5G mobile base stations. In Proceedings of the 10th European Conference on Antennas and Propagation (EuCAP), Davos, Switzerland, 10-15 April 2016.

39. Roh, W.; Seol, J.-Y.; Park, J.; Lee, B.; Lee, J.; Kim, Y.; Cho, J.; Cheun, K.; Aryanfar, F. Millimeter-wave beamforming as an enabling technology for $5 \mathrm{G}$ cellular communications: Theoretical feasibility and prototype results. IEEE Commun. Mag. 2014, 52, 106-113. [CrossRef]

40. Parchin, N.O.; Abd-Alhameed, R.A.; Shen, M. A radiation-beam switchable antenna array for 5G smartphones. In Proceedings of the PhotonIcs \& Electromagnetics Research Symposium (PIERS), Xiamen, China, 17-20 December 2019.

41. Parchin, N.O.; Abd-Alhameed, R.A.; Shen, M. A substrate-insensitive antenna array with broad bandwidth and high efficiency for 5G mobile terminals. In Proceedings of the PhotonIcs \& Electromagnetics Research Symposium (PIERS), Xiamen, China, 17-20 December 2019.

42. Naqvi, A.; Lim, S. Review of recent phased arrays for millimeter-wave wireless communication. Sensors 2018, 18, 3194. [CrossRef]

43. Parchin, N.O.; Abd-Alhameed, R.A.; Shen, M. Frequency-switchable patch antenna with parasitic ring load for $5 \mathrm{G}$ mobile terminals. In Proceedings of the International Symposium on Antennas and Propagation (ISAP), Xi'an, China, 27-30 October 2019.

44. Parchin, N.O.; Alibakhshikenari, M.; Basherlou, H.J.; Abd-Alhameed, R.A.; Rodriguez, J.; Limiti, E. MM-wave phased array quasi-Yagi antenna for the upcoming 5G cellular communications. Appl. Sci. 2019, 9, 978. [CrossRef]

45. Ojaroudiparchin, N.; Shen, M.; Pedersen, G.F. Low-cost planar mm-Wave phased array antenna for use in mobile satellite (MSAT) platforms. In Proceedings of the 23rd Telecommunications Forum Telfor (TELFOR), Belgrade, Serbia, 24-26 November 2015; pp. 528-531.

46. Parchin, N.O.; Al-Yasir, Y.; Basherlou, H.J.; Abdulkhaleq, A.M.; Sajedin, M.; Abd-Alhameed, R.A.; Noras, J.M. Modified PIFA array design with improved bandwidth and isolation for 5G mobile handsets. In Proceedings of the IEEE 2nd 5G World Forum (5GWF), Dresden, Germany, 30 September-2 October 2019.

47. Ojaroudi, N.; Ojaroudi, H.; Ghadimi, N. Quadband planar inverted-f antenna (PIFA) for wireless communication systems. Prog. Electromagn. Res. Lett. 2014, 45, 51-56. [CrossRef]

48. Salonen, P.; Sydänheimo, L.; Keskilammi, M.; Kivikoski, M. A small planar inverted-F antenna for wearable applications. In Proceedings of the IEEE International Symposium on Wearable Computers, San Francisco, CA, USA, 18-19 October 1999; pp. 96-100. 
49. Ojaroudi, N.; Ghadimi, N.; Ojaroudi, Y.; Ojaroudi, S. An omnidirectional PIFA for downlink and uplink satellite applications in C-band. Microw. Opt. Technol. Lett. 2014, 56, 2684-2686. [CrossRef]

50. CST Microwave Studio; Version 2018; CST: Framingham, MA, USA, 2018.

51. Valizade, A.; Ghobadi, C.; Nourinia, J.; Parchin, N.O.; Ojaroudi, M. Band-notch slot antenna with enhanced bandwidth by using $\Omega$-shaped strips protruded inside rectangular slots for UWB applications. Appl. Comput. Electromagn. Soc. J. 2012, 27, 816-822.

52. Bahmani, M.; Mazloum, J.; Parchin, N.O. A compact UWB slot antenna with reconfigurable band-notched function for multimode applications. ACES J. 2016, 13, 975-980.

53. Al-Yasir, Y.; Abd-Alhameed, R.A.; Noras, J.M.; Abdulkhaleq, A.M.; Parchin, N.O. Design of very compact combline band-pass filter for 5G applications. In Proceedings of the 2018 Loughborough Antennas \& Propagation Conference (LAPC), Loughborough, UK, 12-13 November 2013; pp. 1-4.

54. Ojaroudi, N.; Ojaroudi, M.; Amiri, S. Enhanced bandwidth of small square monopole antenna by using inverted U-shaped slot and conductor-backed plane. Appl. Comput. Electromagn. Soc. 2012, 27, 685-690. [CrossRef]

55. Ojaroudi Parchin, N.; Jahanbakhsh Basherlou, H.; Al-Yasir, Y.I.A.; Abdulkhaleq, A.M.; Abd-Alhameed, R.A. Ultra-wideband diversity MIMO antenna system for future mobile handsets. Sensors 2020, 20, 2371. [CrossRef]

56. Jamesn, J.R.; Hall, P.S. Handbook of Microstrip Antennas; Peter Peregrinus Ltd.: London, UK, 1989.

57. Mazloum, J.; Ghorashi, A.; Ojaroudi, M.; Ojaroudi, N. Compact triple-band S-shaped monopole diversity antenna for MIMO applications. Appl. Comput. Electromagn. Soc. J. 2015, 30, 975-980.

58. Valizade, A.; Ojaroudi, M.; Ojaroudi, N. CPW-fed small slot antenna with reconfigurable circular polarization and impedance bandwidth characteristics for DCS/WiMAX applications. Prog. Electromagn. Res. C 2015, 56, 65-72. [CrossRef]

59. Kumar, G.; Ray, K.P. Broadband Microstrip Antennas; Artech House Inc.: Norwood, MA, USA, 2003.

60. Parchin, N.O.; Shen, M.; Pedersen, G.F. End-fire phased array 5G antenna design using leaf-shaped bow-tie elements for 28/38 GHz MIMO applications ICUWB. In Proceedings of the IEEE International Conference on Ubiquitous Wireless Broadband (ICUWB), Nanjing, China, 16-19 October 2016.

61. AI-Yasir, Y.I.A.; Ojaroudi Parchin, N.; Alabdullah, A.; Mshwat, W.; Ullah, A.; Abd-Alhameed, R. New pattern reconfigurable circular disk antenna using two PIN diodes for WiMax/WiFi (IEEE 802.11a) applications. In Proceedings of the IEEE International Conference on Synthesis, Modeling, Analysis and Simulation Methods and Applications to Circuit Design (SMACD), Lausanne, Switzerland, 15-18 July 2019.

62. Zolghadr, J.; Cai, Y.; Ojaroudi, N. UWB slot antenna with band-notched property with time domain modeling based on genetic algorithm optimization. Appl. Comput. Electromagn. Soc. J. 2016, 31, 926-932.

63. Siahkal-Mahalle, B.H.; Ojaroudi, N.; Ojaroudi, M. A new design of small square monopole antenna with enhanced bandwidth by using cross-shaped slot and conductor-backed plane. Microw. Opt. Technol. Lett. 2012, 54, 2656-2659. [CrossRef]

64. Ullah, A.; Parchin, N.O.; Abd-Alhameed, R.A.; Excell, P. Coplanar waveguide antenna with defected ground structure for 5G millimeter wave communications. In Proceedings of the IEEE Middle East \& North Africa COMMunications Conference, Manama, Bahrain, 19-21 November 2019.

65. Ojaroudi, N. Design of microstrip antenna for 2.4/5.8 GHz RFID applications. In Proceedings of the German Microwave Conference, GeMic 2014, RWTH Aachen University, Aachen, Germany, 10-12 March 2014.

66. Ojaroudi, N. Circular microstrip antenna with dual band-stop performance for ultra-wideband systems. Microw. Opt. Technol. Lett. 2014, 56, 2095-2098. [CrossRef]

67. Basherlou, H.J.; Parchin, N.O.; Abd-Alhameed, R.A. MIMO monopole antenna design with improved isolation for 5G WiFi applications. Int. J. Electr. Electron. Sci. 2019, 7, 1-5.

68. Sharawi, M.S. Printed multi-band MIMO antenna systems and their performance metrics [wireless corner]. IEEE Antennas Propag. Mag. 2013, 55, 218-232. [CrossRef]

69. Elfergani, I.T.E.; Hussaini, A.S.; Rodriguez, J.; Abd-Alhameed, R. Antenna Fundamentals for Legacy Mobile Applications and Beyond; Springer: Cham, Switzerland, 2017; pp. 1-659.

70. Parchin, N.O.; Al-Yasir, Y.; Basherlou, H.J.; Abd-Alhameed, R.A. A closely spaced dual-band MIMO patch antenna with reduced mutual coupling for 4G/5G applications. Prog. Electromagn. Res. C 2020, 101, 71-80.

71. Parchin, N.O. Low-profile air-filled antenna for next generation wireless systems. Wirel. Pers. Commun. 2017, 97, 3293-3300. [CrossRef] 
72. Parchin, N.O.; Shen, M.; Pedersen, G.F. Small-size tapered slot antenna (TSA) design for use in 5G phased array applications. Appl. Comput. Electromagn. Soc. J. 2017, 32, 193-202.

73. Ojaroudi, Y.; Ojaroudi, N.; Ghadimi, N. Circularly polarized microstrip slot antenna with a pair of spur-shaped slits for WLAN applications. Microwave Opt. Technol. Lett. 2017, 57, 756-759. [CrossRef]

74. Syrytsin, I.; Zhang, S.; Pedersen, G.F. Performance investigation of a mobile terminal phased array with user effects at 3.5 GHz for LTE advanced. IEEE Antennas Wirel. Propag. Lett. 2017, 16, 1847-1850. [CrossRef]

75. Ojaroudiparchin, N.; Shen, M.; Pedersen, G.F. Design of Vivaldi antenna array with end-fire beam steering function for $5 \mathrm{G}$ mobile terminals. In Proceedings of the 23rd Telecommunications Forum Telfor (TELFOR), Belgrade, Serbia, 24-26 November 2015; pp. 587-590.

76. Khan, R.; Al-Hadi, A.A.; Soh, P.J.; Kamarudin, M.R.; Ali, M.T. User influence on mobile terminal antennas: A review of challenges and potential solution for 5G antennas. IEEE Access 2018, 6, 77695-77715. [CrossRef]

77. Stuchly, M. Electromagnetic fields and health. IEEE Potentials 1993, 12, 34-39. [CrossRef]

78. Hussain, R.; Sharawi, M.S.; Shamim, A. 4-element concentric pentagonal slot-line-based ultra-wide tuning frequency reconfigurable MIMO antenna system. IEEE Trans. Antennas Propag. 2018, 66, 4282-4287. [CrossRef]

79. Ojaroudiparchin, N.; Shen, M.; Zhang, S.; Pedersen, G.F. A switchable 3-D-coverage-phased array antenna package for 5G mobile terminals. IEEE Antennas Wireless Propag. Lett. 2016, 15, 1747-1750. [CrossRef]

80. Parchin, N.O.; Al-Yasir, Y.; Basherlou, H.J.; Noras, J.M.; Abd-Alhameed, R.A. Orthogonally dual-polarized MIMO antenna array with pattern diversity for sub-6 GHz 5G mobile terminals. IET Microw. Antennas Propaga. 2020, 14, 457-467. [CrossRef]

81. Halaoui, M.E.; Kaabal, A.; Asselman, H.; Ahyoud, S.; Asselman, A. Multiband planar inverted-F antenna with independent operating bands control for mobile handset applications. Int. J. Antennas Propag. 2017, 2017, 8794039. [CrossRef]

82. Parchin, N.O.; Al-Yasir, Y.; Abdulkhaleq, A.M.; Elfergani, I.T.E.; Rayit, A.; Noras, J.M.; Rodriguez, J.; Abd-Alhameed, R.A. Frequency reconfigurable antenna array for mm-Wave 5G mobile handsets. In Proceedings of the 9th International Conference on Broadband Communications, Networks, and Systems, Faro, Portugal, 19-20 September 2018.

83. Parchin, N.O.; Shen, M.; Pedersen, G.F. Wideband Fabry-Pérot resonator for $28 \mathrm{GHz}$ applications. In Proceedings of the IEEE International Conference on Ubiquitous Wireless Broadband (ICUWB), Nanjing, China, 16-19 October 2016; pp. 1-4.

84. Li, R.; Zhang, Q.; Kuang, Y.; Chen, X.; Xiao, Z.; Zhang, J. Design of a miniaturized antenna based on split ring resonators for $5 \mathrm{G}$ wireless communications. In Proceedings of the Cross Strait Quad-Regional Radio Science and Wireless Technology Conference (CSQRWC), Taiyuan, China, 18-21 July 2019; pp. 1-4.

85. Liu, D.; Gaucher, B. Design considerations for millimeter wave antennas within a chip package. In Proceedings of the IEEE International Workshop on Anti-counterfeiting, Security, Identification, Xiamen, China, 16-18 April 2007; pp. 13-17.

86. Ojaroudiparchin, N.; Shen, M.; Pedersen, G.F. Investigation on the performance of low-profile insensitive antenna with improved radiation characteristics for the future 5G applications. Microw. Opt. Technol. Lett. 2016, 58, 2148-2158. [CrossRef]

87. Al-Yasir, Y.I.A.; Hasanain, A.H.A.; Baha, A.S.; Parchin, N.O.; Ahmed, M.A.; Abdulkareem, S.A.; Raed, A.A. New Radiation Pattern-Reconfigurable 60-GHz Antenna for 5G Communications. IntechOpen, 2019. Available online: https:/www.intechopen.com/online-first/new-radiation-pattern-reconfigurable-60-ghzantennafor-5g-communications (accessed on 26 September 2019).

88. Gomez-Tagle, J.; Christodoulou, C.G. Broadband characterization of the active reflection coefficient of finite-sized phased array microstrip antennas. In Proceedings of the 2000 IEEE International Conference on Phased Array Systems and Technology (Cat. No.00TH8510), Dana Point, CA, USA, 21-25 May 2000; pp. 255-258.

89. Bai, T.; Heath, R. Coverage and rate analysis for millimeter wave cellular networks. IEEE Trans. Wirel. Commun. 2015, 14, 1110-1114. [CrossRef]

(C) 2020 by the authors. Licensee MDPI, Basel, Switzerland. This article is an open access article distributed under the terms and conditions of the Creative Commons Attribution (CC BY) license (http://creativecommons.org/licenses/by/4.0/). 